\title{
Immunosuppressant and immunomodulatory treatments for multifocal motor neuropathy (Review)
}

\author{
Umapathi T, Hughes RAC, Nobile-Orazio E, Léger JM
}

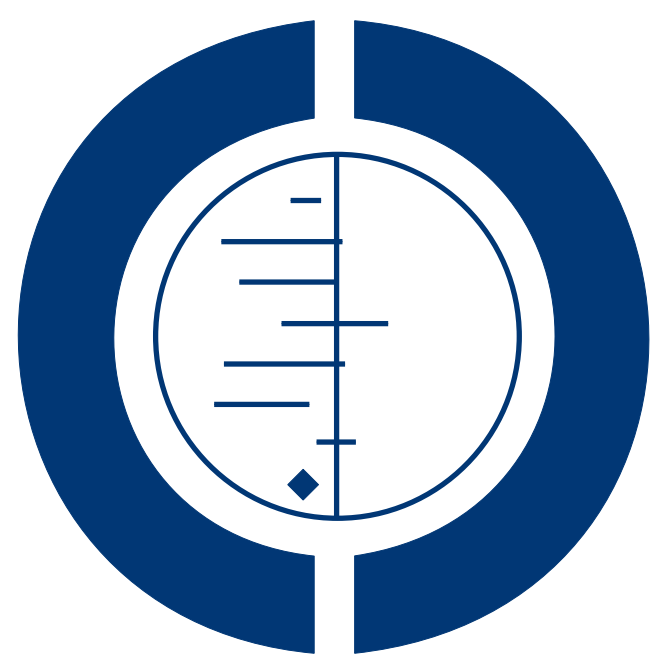

\section{THE COCHRANE COLLABORATION $^{\circledR}$}

This is a reprint of a Cochrane review, prepared and maintained by The Cochrane Collaboration and published in The Cochrane Library 2015, Issue 3

http://www.thecochranelibrary.com

\section{WILEY}

Immunosuppressant and immunomodulatory treatments for multifocal motor neuropathy (Review)

Copyright $\odot 2015$ The Cochrane Collaboration. Published by John Wiley \& Sons, Ltd. 
TABLE OF CONTENTS

HEADER . . . . . . . . . . . . . . . . . . . . . . . . . . . . . . . . . . 1

ABSTRACT . . . . . . . . . . . . . . . . . . . . . . . . . . . . . . . . . . . . . . . . 1

PLAIN LANGUAGE SUMMARY . . . . . . . . . . . . . . . . . . . . . . . . . . . . . . . . . . . .

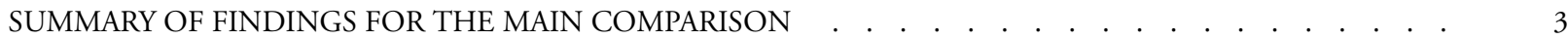

BACKGROUND . . . . . . . . . . . . . . . . . . . . . . . . . . . . . . . . . . . . . . . . . 5

OBJECTIVES . . . . . . . . . . . . . . . . . . . . . . . . . . . . . . . . . . . . . . . . . . . . . . .

METHODS . . . . . . . . . . . . . . . . . . . . . . . . . . . . . . . . . . . . . .

RESULTS . . . . . . . . . . . . . . . . . . . . . . . . . . . . . . . . . . . . . . . 8

Figure 1. . . . . . . . . . . . . . . . . . . . . . . . . . . . . . . . . . . . . . . 9

DISCUSSION . . . . . . . . . . . . . . . . . . . . . . . . . . . . . . . . . . . . . .

AUTHORS' CONCLUSIONS . . . . . . . . . . . . . . . . . . . . . . . . . . . . . . . . . . . .

ACKNOWLEDGEMENTS . . . . . . . . . . . . . . . . . . . . . . . . . . . . . . . . . . . . . . . . .

REFERENCES . . . . . . . . . . . . . . . . . . . . . . . . . . . . . . . . . . . . . . 17

CHARACTERISTICS OF STUDIES . . . . . . . . . . . . . . . . . . . . . . . . . . . . . . 23

DATA AND ANALYSES . . . . . . . . . . . . . . . . . . . . . . . . . . . . . . . . . . . . . . . 28

Analysis 1.1. Comparison 1 Mycophenolate mofetil versus placebo, Outcome 1 Improvement in GNDS after 12 months. 28

Analysis 1.2. Comparison 1 Mycophenolate mofetil versus placebo, Outcome 2 Serious adverse events. . . . . . 29

ADDITIONAL TABLES . . . . . . . . . . . . . . . . . . . . . . . . . . . . . . . . . . . 29

APPENDICES . . . . . . . . . . . . . . . . . . . . . . . . . . . . . . . . . . . . . . . . . .

WHAT'S NEW . . . . . . . . . . . . . . . . . . . . . . . . . . . . . . . . . . . . . . . . . . . . . . . . .

HISTORY . . . . . . . . . . . . . . . . . . . . . . . . . . . . . . . . . . . . . . . . 34

CONTRIBUTIONS OF AUTHORS . . . . . . . . . . . . . . . . . . . . . . . . . . . . . . . . . . . . . . . . .

DECLARATIONS OF INTEREST . . . . . . . . . . . . . . . . . . . . . . . . . . . . . . . 35

SOURCES OF SUPPORT . . . . . . . . . . . . . . . . . . . . . . . . . . . . . . . . . . . . . . . . . . . . .

DIFFERENCES BETWEEN PROTOCOL AND REVIEW . . . . . . . . . . . . . . . . . . . . . . . . . . . . 36

INDEX TERMS . . . . . . . . . . . . . . . . . . . . . . . . . . . . . . . . . . . .

Immunosuppressant and immunomodulatory treatments for multifocal motor neuropathy (Review)

Copyright $\odot 2015$ The Cochrane Collaboration. Published by John Wiley \& Sons, Ltd. 


\title{
[Intervention Review] \\ Immunosuppressant and immunomodulatory treatments for multifocal motor neuropathy
}

\author{
T Umapathi ${ }^{1}$, Richard AC Hughes ${ }^{2}$, Eduardo Nobile-Orazio ${ }^{3}$, Jean-Marc Léger ${ }^{4}$ \\ ${ }^{1}$ Department of Neurology, National Neuroscience Institute, Singapore, Singapore. ${ }^{2}$ MRC Centre for Neuromuscular Diseases, Na- \\ tional Hospital for Neurology and Neurosurgery, London, UK. ${ }^{3}$ IRCCS Humanitas Clinical Institute, Neurology 2, Milan University, \\ Milan, Italy. ${ }^{4}$ National Reference Center for Rare Neuromuscular Diseases, Groupe Hospitalier Pitrie Salpêtrière and University Paris \\ VI, Paris Cedex 13, France \\ Contact address: T Umapathi, Department of Neurology, National Neuroscience Institute, 11 Jalan Tan, Tock Seng, Singapore, 308433, \\ Singapore. umapathi@nni.com.sg. umapathi_thirugnanam@nni.com.sg.
}

Editorial group: Cochrane Neuromuscular Disease Group.

Publication status and date: New search for studies and content updated (no change to conclusions), published in Issue 3, 2015.

Review content assessed as up-to-date: 22 September 2014.

Citation: Umapathi T, Hughes RAC, Nobile-Orazio E, Léger JM. Immunosuppressant and immunomodulatory treatments for multifocal motor neuropathy. Cochrane Database of Systematic Reviews 2015, Issue 3. Art. No.: CD003217. DOI: 10.1002/14651858.CD003217.pub5.

Copyright (C) 2015 The Cochrane Collaboration. Published by John Wiley \& Sons, Ltd.

\begin{abstract}
A B S T R A C T
Background

Multifocal motor neuropathy (MMN) is characterised by progressive, predominantly distal, asymmetrical limb weakness and usually multiple partial motor nerve conduction blocks. Intravenous immunoglobulin (IVIg) is beneficial but the role of immunosuppressive agents is uncertain. This is an update of a review first published in 2002 and previously updated in 2003, 2005,2008 and 2011.
\end{abstract}

Objectives

To assess the effects of immunosuppressive agents for the treatment of multifocal motor neuropathy.

\section{Search methods}

On 22 September 2014 we searched the Cochrane Neuromuscular Disease Group Specialized Register, CENTRAL, MEDLINE, EMBASE and LILACS for trials of MMN. We also searched two trials registers for ongoing studies.

\section{Selection criteria}

We planned to include randomised controlled trials (RCTs) and quasi-RCTs. We considered prospective and retrospective case series and case reports in the Discussion.

\section{Data collection and analysis}

Two review authors searched the titles and abstracts of the articles identified and extracted the data independently.

\section{Main results}

Only one RCT of an immunosuppressive or immunomodulatory agent has been performed in MMN. This study randomised 28 participants and showed that mycophenolate mofetil, when used with IVIg, did not significantly improve strength, function or reduce the need for IVIg. No serious adverse events were observed. The study was deemed at low risk of bias. We summarised the results of retrospective and prospective case series in the discussion.

Immunosuppressant and immunomodulatory treatments for multifocal motor neuropathy (Review)

Copyright @ 2015 The Cochrane Collaboration. Published by John Wiley \& Sons, Ltd. 


\section{Authors' conclusions}

According to moderate quality evidence, mycophenolate mofetil did not produce significant benefit in terms of reducing need for IVIg or improving muscle strength in MMN. Trials of other immunosuppressants should be undertaken.

\section{PLAIN LANGUAGE SUMMARY}

Treatments that suppress or modify the immune system for multifocal motor neuropathy

\section{Review question}

We reviewed the evidence for the benefits and harms of treatments that suppress or modify the immune system in multifocal motor neuropathy (MMN).

\section{Background}

MMN is a rare condition causing progressive weakness of the limbs, especially the hands and arms. This disorder is believed to be driven by an immune-based process. The usual treatment is infusion of immunoglobulin (antibodies purified from the blood) into a vein (IVIg). This is expensive, needs to be repeated every few weeks and is not always completely effective. Immunosuppressive drugs (drugs that suppress immune responses) such as cyclophosphamide, azathioprine, ciclosporin, interferon beta-1a, mycophenolate mofetil and rituximab have been tried as initial or add-on treatments.

\section{Study characteristics}

We found only one randomised controlled trial (RCT), of a drug called mycophenolate mofetil. The trial involved 28 people with MMN.

\section{Key results and quality of the evidence}

The trial provided moderate quality evidence that mycophenolate mofetil, when used with IVIg, did not reduce the requirement for IVIg or improve muscle strength of trial participants with MMN. No serious side-effects were observed. The risk of bias was low in this study. New RCTs of other immunosuppressive drugs are needed to identify beneficial treatments for MMN.

The evidence is current to September 2014. 


\section{SUMMARY OF FINDINGSFOR THE MAIN COMPARISON [Explanation]}

\section{Mycophenolate mofetil versus placebo for multifocal motor neuropathy}

Patient or population: people with multifocal motor neuropathy

Settings: single centre outpatient clinic

Intervention: mycophenolate mofetil versus placebo

\begin{tabular}{|c|c|c|c|c|c|c|}
\hline \multirow[t]{3}{*}{ Outcomes } & \multicolumn{2}{|c|}{ Illustrative comparative risks* $(95 \% \mathrm{CI})$} & \multirow{3}{*}{$\begin{array}{l}\text { Relative effect } \\
\text { (95\% Cl) }\end{array}$} & \multirow{3}{*}{$\begin{array}{l}\text { No of participants } \\
\text { (studies) }\end{array}$} & \multirow{3}{*}{$\begin{array}{l}\text { Quality of the evidence } \\
\text { (GRADE) }\end{array}$} & \multirow[t]{3}{*}{ Comments } \\
\hline & Assumed risk & Corresponding risk & & & & \\
\hline & Placebo & Mycophenolate mofetil & & & & \\
\hline $\begin{array}{l}\text { Improvement in GNDS } \\
\text { after } 12 \text { months }{ }^{1}\end{array}$ & 143 per $1000^{2}$ & $\begin{array}{l}77 \text { per } 1000 \\
\text { (9 to } 752)\end{array}$ & $\begin{array}{l}\text { RR } 0.54 \\
(0.06 \text { to } 5.26)\end{array}$ & $\begin{array}{l}28 \\
\text { (1 study) }\end{array}$ & $\begin{array}{l}\oplus \oplus \oplus \bigcirc \\
\text { moderate }^{3}\end{array}$ & $\begin{array}{l}\text { Not significant. Primary } \\
\text { outcome of the authors, } \\
50 \% \text { reduction of IVIg } \\
\text { dose, achieved by } 1 \\
\text { mycophenolate and } 0 \\
\text { placebo participants, also } \\
\text { not significant }\end{array}$ \\
\hline Serious adverse events & See comment & See comment & Not estimable & $\begin{array}{l}28 \\
\text { (1 study) }\end{array}$ & $\begin{array}{l}\oplus \oplus \oplus \bigcirc \\
\text { moderate }^{3}\end{array}$ & $\begin{array}{l}\text { No serious adverse } \\
\text { events. Headache oc- } \\
\text { curred in } 7 \text { out of } 14 \text { my- } \\
\text { cophenolate and } 1 \text { out of } \\
14 \text { placebo participants, } \\
\text { almost statistically signif- } \\
\text { icant }\end{array}$ \\
\hline
\end{tabular}

*The basis for the assumed risk (e.g. the median control group risk across studies) is provided in footnotes. The corresponding risk (and its $95 \% \mathrm{Cl}$ ) is based on the assumed risk in the comparison group and the relative effect of the intervention (and its $95 \% \mathrm{Cl}$ )

Cl: confidence interval; RR: risk ratio 
GRADE Working Group grades of evidence

High quality: Further research is very unlikely to change our confidence in the estimate of effect

Moderate quality: Further research is likely to have an important impact on our confidence in the estimate of effect and may change the estimate

Low quality: Further research is very likely to have an important impact on our confidence in the estimate of effect and is likely to change the estimate

Very low quality: We are very uncertain about the estimate

GNDS is Guy's Neurological Disability Score, which ranks functional impairment from normal function, zero to impossible to use arm

or leg, five. A single grade change would be noticeable by a person with MMN

Assumed risk is that of the placebo group in the included study.

Only one trial with 28 participants 


\section{B A C K G ROU N D}

\section{Description of the condition}

Multifocal motor neuropathy (MMN) is a distinct clinical entity characterised by progressive, predominantly distal, asymmetrical limb weakness and minimal sensory complaints (Bouche 1995; Chad 1986; ENMC 2001; Krarup 1990; Nobile-Orazio 2001). Cranial and proximal limb muscles are usually spared. The upper limbs, particularly the hands, are more commonly involved than the lower limbs. The diagnostic hallmark of MMN is the presence of multiple motor nerve conduction blocks which are required by the American Association of Electrodiagnostic Medicine (AAEEM) and Peripheral Nerve Society (PNS) consensus criteria (Olney 2003; van Schaik 2006), although a similar clinical syndrome may occur in the absence of such blocks (Chaudhry 2006; Delmont 2006; Slee 2007). MMN is most likely immune-mediated. It shares some characteristics with chronic inflammatory demyelinating polyradiculoneuropathy and the Lewis-Sumner syndrome or multifocal acquired demyelinating sensory and motor neuropathy with persistent conduction block (MADSAM), but is probably a distinct entity (Gorson 1999; Lewis 1982; Lewis 1999; Saperstein 1999; Viala 2004).

In a longitudinal study of 46 people with MMN, followed for a median of 2.3 years, spontaneous improvement or resolution did not occur (Taylor 2000). Repeated administration of intravenous immunoglobulin (IVIg) has become standard treatment for MMN. Various case-reports and small randomised studies supported this practice (Azulay 1994; Charles 1992; Chaudhry 1993; Comi 1994; Cruz 1993; Hoang-Xuan 1993; Léger 1994; Nobile-Orazio 1993; van den Berg 1995; Yuki 1993) Two randomised trials, one with 16 (Federico 2000) and another with 19 (Léger 2001) participants, have confirmed the efficacy of IVIg in MMN. A Cochrane systematic review on the treatment of MMN concluded that IVIg produces significant short-term improvement in strength (van Schaik 2005).

Some people with MMN experience progression of neurological deficits in spite of intensive therapy with IVIg. In a longitudinal study (van den Berg 1998), significant deterioration of strength occurred in some muscle groups, even in participants who were receiving IVIg as often as once weekly. van den Berg-Vos 2002 and Terenghi 2004 also showed that long-term treatment with IVIg may not prevent the reduction of the amplitude of the distal compound muscle action potential which may represent axonal loss. More sustained responses have been reported with larger doses of IVIg. Vucic 2004 treated 10 participants initially with $2 \mathrm{~g} / \mathrm{kg}$ of IVIg monthly for three months. This was followed by fourweekly infusions of IVIg, the dose of which was gradually adjusted so that no functional decline occurred before the next treatment. Changes in IVIg dose were made in steps of $0.4 \mathrm{~g} / \mathrm{kg}$ every fourth week. There was significant and sustained improvement of muscle strength and functional disability in all participants through this period of treatment (range, 3.5 to 12 years). Slee 2007 also reported sustained improvement compared with baseline with a comparable high dose regimen, although gains were not always sustained. A recent study of 88 people with MMN showed that early treatment with IVIg can help reduce permanent deficits from axonal injury (Cats 2010). However, some people with MMN do not respond to IVIg at the outset or require progressively more frequent doses to maintain remission (Azulay 1997; ENMC 2001). For example, in a retrospective study of 40 people with MMN, six out of 20 treatment-naïve individuals did not respond to IVIg at six months, only eight of the 40 participants (22\%) had significant remission at six months, and $25(68 \%)$ were dependent on periodic IVIg infusions (Léger 2008). In Slee 2007, five of 24 people in whom IVIg was tried did not respond.

\section{Description of the intervention}

The inadequate response, high cost and variable availability of IVIg prompted the search for adjunctive immunosuppressive therapies. Cyclophosphamide was the first to be used and was reported to be beneficial when used on its own (Pestronk 1988) or as an adjunctive treatment (Azulay 1997; Meucci 1997). However, cyclophosphamide and other immunosuppressive agents are associated with potentially serious adverse effects. Their use in a relatively benign disease such as MMN requires good evidence for efficacy.

\section{Why it is important to do this review}

When this review was first published in 2002 and then updated in 2004, there were no randomised trials. In 2006, based on nonrandomised studies, a consensus group expressed the opinion that immunosuppressive or immunomodulatory drugs such as cyclophosphamide, ciclosporin, azathioprine, interferon beta-1a or rituximab might be considered if IVIg was not sufficiently effective (van Schaik 2006). In 2007, a high quality trial of mycophenolate mofetil was published and we updated this review to include it in 2008. Mycophenolate mofetil inhibits $\mathrm{T}$ and B lymphocytes by blocking purine synthesis. It has been used to prevent rejection of renal transplants and has low organ toxicity and potential to cause mutations (Allison 2000; Halloran 1997). The possible role of mycophenolate mofetil in the management of myasthenia gravis, myositis and dysimmune neuropathies has been studied (Chaudhry 2001; Ciafaloni 2001; Meriggioli 2003; Mowzoon 2001; Pisoni 2007; Radziwill 2006; Sanders 2008). No further trials were identified at the last update in 2011.

\section{O B J E C T I VES}

To assess the effects of immunosuppressive agents for the treatment of multifocal motor neuropathy. 


\section{METHODS}

\section{Criteria for considering studies for this review}

\section{Types of studies}

We considered for inclusion all randomised controlled trials (RCTs). We also considered quasi-RCTs in which allocation was not random but was intended to be unbiased (e.g. alternate allocation). There were no restrictions as to language of publication. We considered case series in the Discussion only.

\section{Types of participants}

Since there is no specific diagnostic test for multifocal motor neuropathy (MMN), precise case definition is crucial. According to the guidelines set by the European Federation of Neurological Societies/Peripheral Nerve Society (van Schaik 2006), we scrutinised the following aspects of diagnosis in the reports of people with MMN.

\section{Conduction block in nerve conduction tests}

The diagnostic hallmark of MMN is persistent partial motor conduction block, a reduction in the compound muscle action potential (CMAP) amplitude and area after proximal as compared to distal stimulation, at sites not prone to compression (Cornblath 1991; Rhee 1990). There is no universal agreement on what constitutes pathological conduction block in clinical studies. Computer simulation models of rat individual motor unit action potentials (MUAP) have demonstrated that the phenomenon of temporal dispersion with interphase cancellation can reduce the CMAP area by up to $50 \%$ and the amplitude by even more (Rhee 1990). This model has been applied to the forearm segment of the median nerve in humans. It shows that the criteria for conduction block, at least in this nerve segment, may depend not only on the prolongation of the CMAP duration on proximal versus distal stimulation, but also on the absolute duration of the distal CMAP (van Asseldonk 2006). Nevertheless, many investigators have accepted a decrease in the CMAP amplitude of more than 50\% from distal to proximal sites of stimulation, associated with a less than $15 \%$ increase in negative peak duration, as the criterion for pathological conduction block. A reduction in CMAP area of more than $50 \%$ has also been suggested as the criterion (ENMC 2001; van Es 1997). Short segment evaluation of nerves $(2 \mathrm{~cm}$ to $4 \mathrm{~cm}$ ) may allow easier differentiation of conduction block (where there would be an abrupt change in area or amplitude) from temporal dispersion (where the change is gradual) (Cornblath 1991).

With less stringent electrodiagnostic criteria, some believe that there is a risk of including non-MMN cases (ENMC 2001; van Es 1997). However, there is also evidence that otherwise typical MMN may present without overt conduction block (Chaudhry
2006; Delmont 2006; Nobile-Orazio 2002; Pakiam 1998; Slee 2007). For the purpose of this review, we accepted the various diagnostic criteria used by authors of studies provided that they conformed to the spirit of the criteria recently proposed (ENMC 2001; Olney 2003; van Schaik 2006).

\section{Sensory abnormalities}

Sensory nerve pathology has been reported in MMN (Corse 1996). However, sensory symptoms and signs, if present, are not prominent. By contrast 'multifocal demyelinating sensorimotor neuropathy with persistent conduction block' also known as the Lewis-Sumner syndrome has prominent sensory features (Lewis 1982). There is some controversy about whether this condition is distinct or is part of the spectrum of MMN (Lewis 1999; Mezaki 1999; Oh 1997; Oh 2000; Saperstein 1999; van den Berg-Vos 2000a; Viala 2004). However, in order to focus on a homogeneous clinical entity, this review excluded people with MMN with prominent sensory symptoms or signs.

\section{Ganglioside antibodies}

Antibodies to ganglioside GM1 have been reported in 20\% (Lange 1992; Taylor 1996) to 80\% (Kornberg 1994; Pestronk 1990) of people with MMN. In view of the wide variability in their occurrence, and the difference in assay performance between laboratories (Nobile-Orazio 2001; Willison 1999) we did not use the presence of GM1 antibodies as a diagnostic criterion.

\section{Types of interventions}

Treatment with immunosuppressive or immunomodulatory agents, including corticosteroids and plasma exchange but not IVIg. The intervention might have been used alone or in combination with IVIg and compared with placebo, no treatment or another treatment.

\section{Types of outcome measures}

\section{Primary outcomes}

Significant improvement at least six months after randomisation. We considered significant improvement to have occurred if a participant improved by one or more points on the modified Rankin disability scale (van Swieten 1988). This scale has the following grades:

0: asymptomatic;

1: non-disabling symptoms not interfering with lifestyle;

2: minor disability symptoms leading to some restriction of lifestyle but not interfering with the person's capacity to look after themselves;

3: moderate disability symptoms significantly interfering with lifestyle or preventing fully independent existence; 
4: moderately severe disability symptoms preventing independent existence although people do not need constant attention day and night;

5: totally dependent, requiring constant attention day and night. We would have converted any other similar disability scales (for example a functional scale for upper and lower limbs (NobileOrazio 1993)) so that a one point change would have been similar to the modified Rankin scale.

\section{Secondary outcomes}

1. Significant improvement at least six months after randomisation on impairment scales such as the Medical Research Council (MRC) sum score (Kleyweg 1991) or grip strength. The MRC score rates each muscle group from zero = no movement to five $=$ full power. The MRC sum score is the sum of the scores of six upper and six lower limb muscle groups giving a maximum of 60 . We would have considered a change of at least one point in the MRC score to be significant in studies evaluating improvement in a single muscle, and a change of at least five per cent in the MRC sum score in studies evaluating improvement in several muscles.

2. Requirement for IVIg treatment before and after at least six months of treatment with immunosuppressive agents, calculated as the cumulative dose in $\mathrm{g} / \mathrm{kg} / \mathrm{month}$ and compared between the treated and control groups.

3. Improvement in motor conduction block after at least six months; defined as either resolution of conduction block (as described above) or statistically significant improvement in the degree of partial conduction block in the nerves studied. Previous studies have reported variable correlation between improvement of conduction block and clinical response to treatment (Federico 2000; Léger 2001; Léger 2008).

4. Serious adverse events attributable to the use of immunosuppressive agents. We defined serious adverse events as any event that:

i) was fatal;

ii) was life threatening (places the person at immediate risk of death);

iii) required or prolonged hospitalisation;

iv) was severely or permanently disabling; or

v) resulted in the development of a malignancy

\section{Search methods for identification of studies}

We revised the search strategies for this update for all databases. We searched the Cochrane Neuromuscular Disease Group Specialized Register (22 September 2014), CENTRAL (2014, Issue 7 in The Cochrane Library), MEDLINE (January 1966 to September 2014), EMBASE (January 1980 to September 2014) and LILACS (January 1982 to September 2014) on 22 September 2014. MMN has only been recognised as a clinical entity since the late 1980s (Chad 1986; Krarup 1990; Parry 1985; Pestronk 1988; Roth 1986). To avoid missing earlier reports without the diagnostic label of MMN, we also used the keywords 'conduction block' and 'motor neuropathy' for the search.

\section{Electronic searches}

The revised search strategies are detailed in Appendix 1 (Cochrane Neuromuscular Disease Group Specialized Register), Appendix 2 (CENTRAL), Appendix 3 (MEDLINE), Appendix 4 (EMBASE) and Appendix 5 (LILACS).

\section{Searching other resources}

We searched ClinicalTrials.gov (www.clinicaltrials.gov) and the World Health Organization Clinical Trials Registry Platorm (ICTRP) (www.who.int/ictrp/en/) for ongoing trials on 3 January 2015. Additionally, we checked references in papers on MMN to identify any additional published or unpublished data.

\section{Data collection and analysis}

\section{Selection of studies}

Two authors independently scrutinised the full text of all relevant identified studies and selected trials that fitted the inclusion criteria. If there had been any disagreements, we would have resolved them by discussion and consultation with the other review authors.

\section{Data extraction and management}

Two authors performed data extraction independently using a specially designed form. We collected data on trial design, participant characteristics, outcomes, interventions and comparators, methods (including risk of bias), results, funding sources and conflicts of interest among main investigators. We would have contacted authors of studies for missing information if necessary. We checked data and entered them into the computer twice to minimise transcription errors. We would have resolved any disagreement by consultation among the review authors.

\section{Assessment of risk of bias in included studies}

Following the guidance in The Cochrane Handbook for Systematic Reviews of Interventions (Higgins 2011), we completed a 'Risk of bias' table, addressing the following domains: sequence generation, allocation concealment, blinding of participants and personnel, blinding of outcome assessors, incomplete outcome data, selective outcome reporting and other issues. We made a judgement about the risk of bias for each entry, of "Low risk of bias", "High risk of bias" or "Unclear risk of bias". We would have resolved any disagreement by discussion among the review authors. 


\section{Measures of treatment effect}

We reported risk ratios (RRs) or risk differences (RDs), with 95\% confidence intervals (CIs), for dichotomous outcomes. For continuous outcomes we derived mean differences (MDs) and 95\% CIs.

\section{Unit of analysis issues}

There were no unit of analysis issues. We would have dealt with these according to the guidance in The Cochrane Handbook for Systematic Reviews of Interventions (Higgins 2011).

\section{Assessment of heterogeneity}

If more than one study had been available and the results had been heterogeneous ( $\mathrm{I}^{2}$ statistic > 40\% (Higgins 2003), we would have performed sensitivity analyses on the basis of individual aspects of risk of bias. We would have conducted subgroup analyses for each immunosuppressive agent.

\section{Data synthesis}

We would have calculated a treatment effect across the trials using the Cochrane statistical package Review Manager 5 (RevMan) (RevMan 2014) if more than one study had been available. If there had been no heterogeneity,

we would have used a fixed-effect model and performed a sensitivity analysis with a random-effects model according to The Cochrane Handbook for Systematic Reviews of Interventions (Higgins 2011).

\section{'Summary of findings' table}

We created a 'Summary of findings' table for the following outcomes.

1. Improvement in neurological disability score after 12 months.

2. Serious adverse events.

We used the five GRADE considerations (study limitations, consistency of effect, imprecision, indirectness and publication bias) to assess the quality of a body of evidence (studies that contribute data for the prespecified outcomes). We used methods and recommendations described in Section 8.5 and Chapter 12 of the Cochrane Handbook for Systematic Reviews of Interventions (Higgins 2011) using GRADEpro software (GRADEpro 2014). We justified all decisions to down- or up-grade the quality of studies using footnotes and we made comments to aid reader's understanding of the review where necessary.

\section{Subgroup analysis and investigation of heterogeneity}

If more than one study had been available and the results had been heterogeneous, we would have performed sensitivity analyses on the basis of individual aspects of risk of bias. We would have conducted subgroup analyses for each immunosuppressive agent.

\section{R E S U L T S}

\section{Description of studies}

\section{Results of the search}

In the previous versions of this review only one study met the selection criteria. For this update the numbers of new papers found by the revised strategies were 73 in MEDLINE, 58 in EMBASE, none in LILACS, six in the Cochrane Neuromuscular Disease Group Specialized Register and three in CENTRAL. After deduplication there were 105 references but none met the inclusion criteria for the review. We identified no potentially eligible ongoing trials in clinical trials registers.

\section{Included studies}

The one previously included trial (see Characteristics of included studies) was a randomised, single-centre, placebo-controlled, 'addon' study of mycophenolate mofetil $1 \mathrm{~g}$ twice daily for one year (Piepers 2007). Randomisation was stratified for the extent of weakness at baseline. This was to ensure that the baseline strength for both the treatment and placebo groups was similar. Three months later intravenous immunoglobulin (IVIg) dose was reduced until a decline in muscle strength and functional status was observed. The primary endpoint was $50 \%$ or more reduction of mean weekly IVIg dose. Secondary outcome measures were improvement of muscle strength and functional status at three months, and a reduction of immunoglobulin M (IgM) GM1 antibody titre after 12 months of treatment. Muscle strength was assessed using a modified Medical Research Council (MRC) sum score of 15 muscles on both sides, making the maximum score 150. Grip strength and strength of weak muscles was quantified using a hand-held dynamometer. Functional assessment was performed using: (1) Guy's Neurological Disability Scale (Sharrack 1999), which rates limbs from zero $=$ normal functioning to five = impossible to use the limb; (2) the self evaluation scale (Léger 2001), which scores five daily motor activities that are selected by the participant and the physician at baseline, zero indicating normal functioning and five impossible to perform activity; and (3) the nine-hole peg test (Oxford 2003; Sharrack 1999).

The participants were receiving regular IVIg every two to five weeks. IVIg was reduced $5 \mathrm{~g}$ per administration if the weekly dose equalled or exceeded $15 \mathrm{~g} /$ week and $2.5 \mathrm{~g}$ per administration if the weekly dose was lower than $15 \mathrm{~g} /$ week. This reduction was discontinued if: (a) at least a one-point reduction was observed on the Guy's Neurological Disability Scale, or an increase of one point on at least two items on the self evaluation scale; or (b) dynamometry showed a $50 \%$ decline in muscle strength in at least two clinically affected muscles; or (c) participants reported an unacceptable decline in daily functioning. In such a case, IVIg 
was increased and when the participant was stable again another reduction was attempted. If the participant deteriorated again, IVIg dose reduction was abandoned.

Twenty-eight participants were randomised from an initial cohort of 65 participants that were considered. Twenty-four of the 28 participants satisfied criteria for definite multifocal motor neuropathy (MMN), three for probable MMN and one for possible MMN. One participant that was initially enrolled was excluded from randomisation because of large fluctuations in muscle strength. The baseline characteristics, in particular the mean duration of IVIg maintenance treatment, mean IVIg dose per week, muscle strength and functional scores were similar between the mycophenolate mofetil treated and placebo groups. Two participants withdrew from the study after three months, one was taking mycophenolate mofetil and complained of flu-like symptoms. The other was on placebo and was deteriorating rapidly. These subjects were included so an intention-to-treat analysis was performed. None was lost to follow-up.

In the absence of RCTs of other agents, we have summarised the observational studies in the Discussion.

\section{Risk of bias in included studies}

The one included study (Piepers 2007) had a low risk of bias, having adequate allocation concealment, comparison of experimental groups, explicit diagnostic criteria, completeness of follow-up, blind outcome assessment and blind administration of treatment (Figure 1, Characteristics of included studies). Intention-to-treat analysis was performed. No participant was lost to follow-up. The small size of the trial reduced the grading of evidence quality in Summary of findings for the main comparison to moderate. However, in this rare disease, recruiting so many participants was a remarkable achievement.

Figure I. Risk of bias summary: review authors' judgements about each risk of bias item for each included study. Green (+) = low risk of bias.

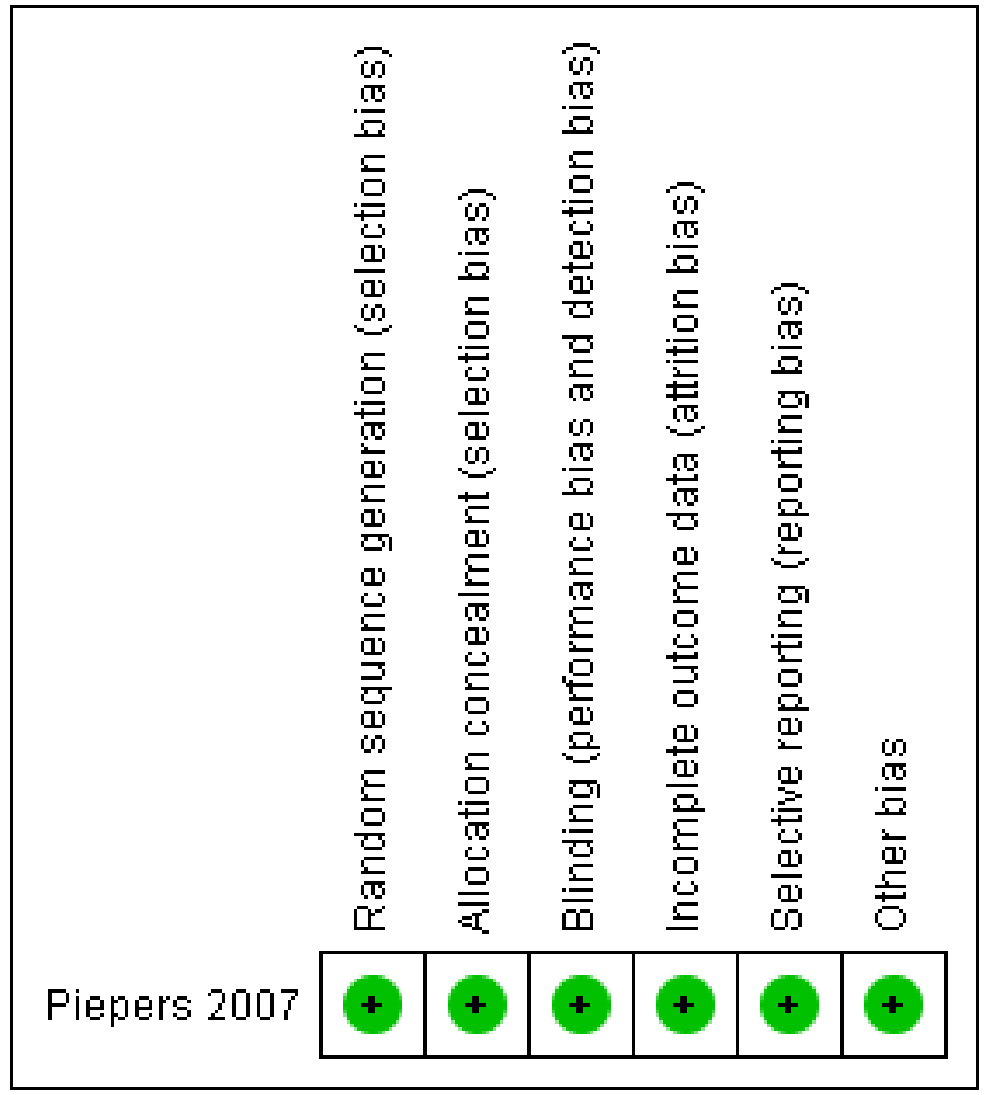

Immunosuppressant and immunomodulatory treatments for multifocal motor neuropathy (Review) 


\section{Effects of interventions}

See: Summary of findings for the main comparison Mycophenolate mofetil versus placebo for multifocal motor neuropathy

The only RCT tested mycophenolate mofetil. We report in this section first the outcomes selected in the protocol for this review and then the other outcomes reported by the authors of the trial.

\section{Primary outcome measure}

\section{Significant improvement at least six months after randomisation}

Scores for the Rankin scale were not available but the authors reported the mean (SD) scores for the Guy's Neurological Disability Scale (Sharrack 1999) at 3, 6 and 12 months. This measurement in this trial was difficult to interpret because the trial design demanded the stepwise reduction in IVIg dose after three months, which might have confounded the comparison of improvement in disability at later visits. Increasing scores on this scale indicate worse disability. At 12 months, the score improved by at least one point in one out of 13 mycophenolate mofetil and two out of 14 placebo participants, RR 0.54 (95\% CI 0.06 to 5.26) in favour of placebo (see Analysis 1.1 and Summary of findings for the main comparison). The results at three and six months also showed no statistically significant differences between treatment and control groups.

The trial authors also measured disability with the Léger 2001 self evaluation scale in which the participant scores their own ability to perform five selected tasks appropriate to them on a scale from zero $=$ normal to five $=$ impossible. At 12 months, the score improved by at least one point in three of 14 placebo and none of 14 mycophenolate mofetil participants. The RR is impossible to determine with zero responders in a group, but the risk of improvement was not significantly different, being $21.43 \%$ (95\% CI - 0.07 to 42.92) lower (worse) in the mycophenolate mofetil group. The results at three and six months were also not significant.

\section{Secondary outcome measures}

Significant improvement at least six months after randomisation, on impairment scales

There were no significant differences in the MRC sum score or nine-hole peg board time at baseline, 3, 6 or 12 months between the mycophenolate mofetil and the placebo groups. After 12 months, there was a very small deterioration in the mean (standard deviation (SD)) MRC sum scores of both groups: -1.70 (5.91) in the mycophenolate mofetil group and -1.66 (5.41) in the placebo group without any significant difference between them: MD 0.04 (95\% CI -4.46 to 4.54 ) more deterioration in the mycophenolate mofetil group.
After 12 months, the mean right hand nine-hole peg test time decreased (improved) slightly by -2.05 (7.17) seconds in 13 mycophenolate mofetil participants and increased (worsened) slightly by 0.51 (5.87) seconds in 14 placebo participants; the MD was non-significantly less (faster, that is, better) in the mycophenolate mofetil group, -2.56 seconds ( $95 \%$ CI -12.58 to 7.46 ).

There were also no significant differences in the left hand nine-hole peg test time at 12 months or in any of these outcome measures at three and six months.

Requirement for IVIg treatment before and after at least six months of treatment with immunosuppressive agents

There were no significant differences in the IVIg dose after six or 12 months, the primary outcome measure selected by the trial authors. We calculated the mean change in IVIg dose from baseline which was 2.48 (8.67) $\mathrm{g}$ in the mycophenolate mofetil group compared with $4.02(10.44) \mathrm{g}$ in the placebo group. The MD, $1.54 \mathrm{~g}$ (95\% CI $-9.18 \mathrm{~g}$ to $6.10 \mathrm{~g})$ less in the mycophenolate mofetil group, was not significant.

Improvement in motor conduction block after at least six months

This outcome was not reported.

\section{Serious adverse events}

There were no serious adverse events in the trial. Mycophenolate mofetil was well tolerated. The only minor side-effect, which was significantly more common in the mycophenolate mofetil group, was headache. It occurred in seven out of 14 mycophenolate mofetil participants and only in one out of 14 placebo participants (see Summary of findings for the main comparison), so that the risk of headache was almost significantly higher with mycophenolate mofetil, RR 7.00 (95\% CI 0.99 to 49.69).

\section{Other measures reported by the trial authors.}

Antibody titres of IgM antibodies to ganglioside GM1 did not change significantly after one year of treatment.

\section{DISCUSSION}

\section{Introduction}

Because of the expense, inconvenience and only partial response of multifocal motor neuropathy (MMN) to intravenous immunoglobulin (IVIg) explained in the Background, there had been 
several case reports and series on the use of immunosuppressive treatments such as cyclophosphamide when we first published this review in 2002 and revised it in 2004. For the update in 2008, one randomised controlled trial (RCT) had been published and this tested mycophenolate mofetil. In this Discussion we will first consider this trial and the limited non-randomised evidence concerning mycophenolate mofetil and then consider in turn the nonrandomised evidence concerning other agents. In the 2014 update we did not discover any new trials but updated the review of non-randomised studies. It is not possible to identify all non-randomised studies in this rare and recently described condition, but as four neurologists with extensive experience of this disease we expect to have included at least all consecutive series of more than 10 people with MMN. If readers know of other series of at least this size, we would be pleased to be informed. We have presented primary and second-line or adjunctive treatments separately.

\section{Mycophenolate mofetil}

The single small trial identified showed no benefit either in terms of improvement in functional scales, which was the primary outcome pre-selected for this review, or in reduction of IVIg requirement, the primary outcome selected by the trial authors. The question arises whether this negative trial had adequate power to rule out a clinically important effect of mycophenolate mofetil in this disease. The primary outcome for this review could only be measured after three months which would be enough to detect changes following improvement in conduction block but not to detect the effects on axonal regeneration. The careful follow-up observations over the full 12-month period did not indicate significant improvement. Furthermore, as the trial authors discuss, the beneficial effects of IVIg in other autoimmune disorders are seen at a median period of 11 weeks. Nevertheless, if one accepts that detecting $10 \%$ of responders in the treatment group compared to zero responders in the placebo group would be worthwhile, then with a five per cent level of significance and $80 \%$ power, a trial would require 117 in each group or 234 in total (assuming equal numbers in each group) without any allowance for dropouts. These are much larger numbers than have so far been achieved in MMN trials.

There is only limited evidence in the non-randomised literature concerning mycophenolate mofetil. One person with MMN refractory to other treatments did not respond to $1000 \mathrm{mg}$ mycophenolate mofetil given twice a day for five months (Umapathi 2002). Benedetti 2004 administered $1 \mathrm{~g}$ of mycophenolate mofetil twice a day to four people with MMN who were receiving regular IVIg for six to 12 months. After four months, two individuals, one of whom was also on cyclophosphamide, could stop IVIg. One person could reduce the IVIg infusion by $50 \%$ after four months. Another, who was also on azathioprine, could reduce the IVIg dose by $25 \%$ but only for four months. However, both of the people on cyclophosphamide and azathioprine could discontinue these drugs after about three months of mycophenolate-IVIg combination treatment. Unfortunately, two of the four people with MMN treated eventually had to discontinue mycophenolate mofetil because of weight loss, anorexia, abdominal pain and raised serum amylase. This limited evidence is trivial compared with the results of Piepers 2007. It does, however, keep alive the possibility that there are a small number of people who, like one in the Piepers 2007 trial, become able to reduce or stop IVIg. As argued in the previous paragraph, It would take a much larger trial to discover whether mycophenolate mofetil has this effect in, say, $10 \%$ of people with MMN.

\section{Immunosuppressive agents as primary therapy for multifocal motor neuropathy}

\section{Cyclophosphamide}

Primary treatment of MMN with immunosuppressive agents was first explored in reports that appeared in the late 1980s, when the entity of MMN was being recognised. Pestronk 1988 reported that intravenous cyclophosphamide $\left(3 \mathrm{~g} / \mathrm{m}^{2}\right)$ followed by oral cyclophosphamide produced marked improvement of limb strength in two people after prednisone $100 \mathrm{mg}$ daily for four to six months and plasma exchange had failed. Intravenous cyclophosphamide decreased the white blood cell counts of both the individuals treated to below 2000/ $\mu$ l. Two years later Pestronk 1990 reported the efficacy of cyclophosphamide in five people with MMN.

Subsequently an open label-study by Feldman et al. supported the efficacy of cyclophosphamide as primary treatment in MMN (Feldman 1991). The 13 participants in this study had had symptoms for between one and 20 years. Nine participants were treated with intravenous cyclophosphamide $\left(3 \mathrm{~g} / \mathrm{m}^{2}\right)$ followed by oral cyclophosphamide $(2 \mathrm{mg} / \mathrm{kg} /$ day). Eight showed clinical improvement of at least one Medical Research Council (MRC) grade during the first two to five months of treatment. Of note, three relapsed three to six months after stopping treatment. The side effects reported were alopecia and mild leucopenia. All participants had previously been treated with high-dose prednisone without clinical response. Four showed no improvement with plasma exchange.

Tan 1994 conducted a prospective, uncontrolled treatment trial using cyclophosphamide and prednisolone on participants with various forms of motor neuropathy. Eight participants who had a lower motor neuron syndrome associated with partial conduction block (more than 20\% drop in amplitude and area of compound muscle action potential) received intravenous cyclophosphamide $\left(3 \mathrm{~g} / \mathrm{m}^{2}\right)$ followed a month later by oral cyclophosphamide $(2 \mathrm{mg} /$ $\mathrm{kg} /$ day for six months). Five participants had a response, defined as improvement of their average muscle score (derived from the assessment of 28 muscle groups, graded according to an expanded 10 -point scale) by more than 0.3 units. Six of these participants had not responded in the first phase of the study, in which they had 
received four days of intravenous methylprednisolone followed by $100 \mathrm{mg}$ of prednisolone every other day. Overall, only one participant out of eight with lower motor neuron weakness and partial conduction block responded to corticosteroids in the first phase. Side effects reported among all the 45 participants treated with cyclophosphamide in this trial (which consisted of participants with various upper and lower motor neuron syndromes) included haematuria, leucopenia, persistent diarrhoea and one participant with pneumonia.

In a series of nine people with MMN (Chaudhry 1993), cyclophosphamide improved strength in all three people treated with this drug. Prednisone did not improve any of six people with MMN and plasma exchange did not help either of two. Interestingly, the three people initially treated with cyclophosphamide were later noted to experience greater improvement of strength with IVIg treatment. One person, who received a cumulative dose of $90 \mathrm{~g}$ cyclophosphamide, developed acute myelogenous leukaemia and died from complications of bone marrow transplantation (Chaudhry 1996).

One person in Kaji 1993, a report on the pathology of nerves affected in MMN, improved on $100 \mathrm{mg}$ /day of cyclophosphamide for 10 months. A year earlier, the same group reported a person with MMN who did not respond to the same dose of cyclophosphamide. However, it was given for only one month and was combined with corticosteroids and plasma exchange (Kaji 1992). In a report of two people with MMN (Donaghy 1994), both improved when treatment was switched to cyclophosphamide 100 $\mathrm{mg}$ day from corticosteroids but one subsequently developed listeria meningitis and died from overwhelming abdominal sepsis. Another person improved on oral cyclophosphamide $(2 \mathrm{mg} / \mathrm{kg} /$ day) after an unsatisfactory response to high doses of corticosteroids (oral prednisolone and intravenous methylprednisolone) combined with plasma exchange and azathioprine $(150 \mathrm{mg} /$ day $)$ (Pringle 1997).

The efficacy of cyclophosphamide was mixed in another report of three people with MMN (Krarup 1990): one responded to intravenous cyclophosphamide (total $3 \mathrm{~g} / \mathrm{m}^{2}$ ), followed by oral cyclophosphamide (50 mg/day to $150 \mathrm{mg} /$ day), while one did not respond to a six-month regimen of oral cyclophosphamide (150 $\mathrm{mg}$ /day). Prednisolone was ineffective in all. In a series of five people with MMN, none responded to cyclophosphamide, steroids or plasma exchange, but all responded to IVIg (Comi 1994). In another series of five people with MMN, two not improving or stabilizing after a regimen of IVIg followed by azathioprine and prednisolone slightly improved or stabilized after nine months of intravenous cyclophosphamide at a dose of $1 \mathrm{~g} / \mathrm{m}^{2}$ and $700 \mathrm{mg} /$ $\mathrm{m}^{2}$ (Ronquillo 2001).

Pestronk 2002 expressed the opinion, on the Washington University at St Louis Neuromuscular Diseases website, that six-monthly treatment with $1 \mathrm{~g} / \mathrm{m}^{2}$ of cyclophosphamide, each preceded by two plasma exchanges could induce long-term improvement (and reduction of GM1 antibodies) and is associated with fewer adverse events than cyclophosphamide at $3 \mathrm{~g} / \mathrm{m}^{2}$.

\section{Corticosteroids}

In addition to the reports mentioned above (Chaudhry 1993; Comi 1994; Feldman 1991; Krarup 1990; Pestronk 1988; Pringle 1997; Tan 1994), a number of authors have highlighted the lack of efficacy of corticosteroids in MMN. Pestronk 1990 reported that out of seven people, only one improved on high-dose corticosteroids (details of the treatment regimen were not given). We have listed other case reports on the lack of efficacy of corticosteroids in MMN in Table 1. A number of reports have highlighted the possible deleterious effect of corticosteroids in MMN (see Table 2). However, a few reports have suggested a possible benefit of corticosteroid therapy for MMN (see Table 3).

\section{Plasma exchange}

Various reports and anecdotal experience have suggested that unlike in chronic inflammatory demyelinating polyradiculoneuropathy, plasma exchange may not be efficacious in MMN (Chaudhry 1993; Pestronk 1988; Pringle 1997; Vrethem 1996). One person, described by Beydoun 1998, showed modest improvement after six courses of plasma exchange. This response apparently waned. However, there was prompt and marked improvement in strength after a course of IVIg. This was sustained on monthly IVIg infusions. In the series reported in Krarup 1990, of the two people treated with plasma exchange, only one showed a mild effect. Carpo 1998 reported an individual with motor neuropathy who worsened clinically and on electrophysiological parameters after plasma exchange. Conduction block developed in previously unaffected nerves. The person then improved after IVIg infusion. A similar case of a person with MMN who deteriorated after plasma exchange and subsequently improved on reinstating IVIg was reported in Claus 2000. Beydoun 2000 reported a person with MMN who presented with bilateral phrenic neuropathy whose respiratory function improved significantly with 14 plasma exchanges in three months. Subsequent limb weakness was successfully treated with IVIg.

Seven cycles of immunoabsorption over 97 days were ineffective in the person with MMN whose case was reported by Finsterer 1999a. In the largest retrospective series (Lehmann 2008), there was no electrophysiological improvement and only two of seven people treated improved clinically after PE (four to 18 treatments). Cerebrospinal fluid filtration was also reported to be ineffective in a person who had a good response to IVIg (Finsterer 1999).

\section{Interferon beta}

Three people with disease duration of seven to nine years resistant to other treatments were given interferon beta-1a, six million international units subcutaneously three times a week for six months (Martina 1999). All improved clinically in the first three months 
of therapy and remained stable during the period of follow-up. However, improvement on the Rankin scale was only documented in one participant. The recorded side effects were flu-like symptoms, fever, sweating and erythema at injection sites. In a study of interferon beta-1a in nine people (van den Berg-Vos 2000b), four had received only one course of IVIg while the rest were on regular infusions before the start of interferon beta- 1 a. Three participants responded, apparently better than to IVIg. Six did not respond, of whom four deteriorated. Interestingly five of the six non-responders were on maintenance IVIg prior to start of the trial. Four of these participants received additional IVIg during the trial. The authors speculated that IVIg might have interfered with the action of interferon beta-1a. The non-responders could also have been advanced cases and therefore less likely to respond. However, the people who responded to interferon in the Martina 1999 report were chronic cases who had failed other therapy. Interferon shares the low toxicity profile of IVIg and is easier to administer. However, the cost with prolonged use is also high.

\section{Ciclosporin}

Two people, one with a 12-year and one with a two-year history responded within two months to ciclosporin $5 \mathrm{mg} / \mathrm{kg} /$ day (Nemni 2003). In the second case the drug was discontinued after one year and the person continued to be in remission for 39 months. The authors felt that the immunophilin-ligand effect as well as the immunosuppressive effect of ciclosporin may have been responsible for its efficacy.

\section{Azathioprine}

Hausmanowa-Petrusewicz 1991 described a individual with MMN who did not respond to initial treatment with oral steroid but started to improve 12 months after starting azathioprine 100 mg per day (it was unclear whether the individual was continuing steroids). Bouche 1995 reported that azathioprine stabilised one of the two people not responsive to IVIg. The single individual with MMN in Krarup 1990 who was treated with azathioprine $200 \mathrm{mg} /$ day did not improve.

\section{Rituximab}

Rituximab is a monoclonal antibody directed against the B cell surface marker CD20. In a study of this drug in 21 people suffering from various polyneuropathies, 14 had MMN, of whom nine had raised IgM GM1 antibody levels (Pestronk 2003). The majority had stopped or never did respond to IVIg. The treatment consisted of four intravenous weekly infusions of rituximab, $375 \mathrm{mg} /$ $\mathrm{m}^{2}$. Eight to 15 months later, about two-thirds of the participants received repeat doses of rituximab, initially two-weekly and then once every ten weeks. The response was compared with a noncontemporaneous cohort of 13 participants, eight of whom had MMN. At two years, the participants' strength increased by about a fifth while no significant change was noted in the comparison group. The treatment was well tolerated. Light headedness, chills and hypotension associated with the infusion improved after slowing the rate of administration. Stieglbauer 2009 reported three people with MMN, who had become increasingly less responsive to IVIg but showed clinical improvement following rituximab monotherapy. Michaud 2011 reported one person in whom the addition of rituximab to IVIg appeared to cause improvement in strength and disability for at least three years, although cyclophosphamide, azathioprine and mycophenolate had not been effective. However, not all the reports have been favourable. In one single case report, a person who had previously received IVIg, a similar regimen was followed after two months by worsening and no reduction of IgM GM1 titres (Rojas-Garcia 2003).

\section{Infliximab}

A number of cases of peripheral neuropathy associated with the use of tumour necrosis factor alpha (TNF-alpha) blocking therapy, particularly infliximab, have been reported. Some of these people have features of MMN (Cocito 2005; Fardet 2007; Rodriguez-Escalera 2005; Singer 2004; Tektonidou 2007), although cases of multi-focal chronic inflammatory demyelinating polyneuroradiculopathy (Richez 2005), Guillain-Barré syndromelike illness (Cisternas 2002), vasculitic multiple mononeuropathy (Jarrett 2003; Richette 2004) and subacute sensorimotor neuropathy (Tektonidou 2007) have also been described. The lagtime between therapy and the development of neuropathy varies from three to 24 months (Rodriguez-Escalera 2005; Singer 2004; Tektonidou 2007). Spontaneous recovery is observed with withdrawal of infliximab in some people with MMN (Singer 2004; Richez 2005). Others require immunosuppressive treatment ( Kosa 2009; Lozeron 2009; Tektonidou 2007). An increase of serum TNF-alpha level in people with MMN after IVIg infusion and in parallel with clinical improvement has also been reported (Terenghi 2006). The role of TNF in MMN and the reason for the possible induction of MMN by antibodies to it are not known. Nevertheless, with the present experience, it would be prudent not to attempt treating MMN with TNF-blocking agents.

\section{Summary of the evidence for immunosuppressive and immunomodulatory agents as treatment for multifocal motor neuropathy}

In summary, the available non-randomised evidence suggests a possible therapeutic role of cyclophosphamide in the primary treatment of MMN, provided it is given at an adequate dose. Its efficacy perhaps may even be comparable to IVIg. However, even the small number of people with MMN reported to date confirm the experience from treatment of other diseases that cyclophosphamide has significant adverse effects, some of which are delayed by a number of years. Unfortunately there are insufficient data on the effect of less toxic cytotoxic agents such as ciclosporin 
and azathioprine in the primary treatment of MMN. Similarly, the efficacy of immunosuppressants such as rituximab and mycophenolate mofetil as primary or lone treatment of MMN is unclear. Corticosteroids and plasma exchange are probably ineffective. There are so many reports of corticosteroids worsening MMN as to discourage investigation of its therapeutic role. There is also suggestion that plasma exchange may occasionally actually worsen MMN. Interferon beta-1a is a relatively safe, albeit expensive alternative which might be worth further investigation.

\section{Immunosuppressive agents as adjunctive treatment}

The demonstrable efficacy of IVIg in MMN has prompted some authors to start treatment with IVIg, and then add an immunosuppressive agent to reduce the need for frequent IVIg infusions or to improve the clinical response. Younger age of onset (van den Berg-Vos 2000c), fewer affected limbs (van den Berg-Vos 2000c), creatine kinase level less than 180 U/L (van den Berg-Vos 2000c), elevated anti-GM1 antibody titres (Azulay 1997; van den Berg-Vos 2000c), definite evidence of conduction block (van den Berg-Vos 2000c) and lack of amyotrophy (Bouche 1995) have been suggested as factors that predict a good response to IVIg. More intensive therapy with IVIg may also prevent long-term neurological deterioration (Vucic 2004). Such prognostic factors, if they were well validated, might help select people with MMN who may not respond to IVIg alone and therefore benefit from the early introduction of another therapeutic modality. The RCT included in this review (Piepers 2007), did not demonstrate an adjunctive effect of mycophenolate mofetil when used with IVIg.

What is then the available evidence from uncontrolled studies for immunosuppressants as adjuncts in the treatment of MMN?

\section{Cyclophosphamide}

In an open label trial of six participants treated with IVIg and cyclophosphamide (Meucci 1997), all responded to an initial course of IVIg and were maintained on periodic infusions. Oral cyclophosphamide was started at $1.5 \mathrm{mg} / \mathrm{kg}$ to $2 \mathrm{mg} / \mathrm{kg}$ and then subsequently adjusted $(0.5 \mathrm{mg} / \mathrm{kg}$ to $3 \mathrm{mg} / \mathrm{kg})$ to maintain the white cell count between $3000 / \mu \mathrm{l}$ to $3500 / \mu \mathrm{l}$. The follow-up period was 37 to 61 (mean 47) months. After three to seven months of oral cyclophosphamide, the interval between IVIg infusions could be progressively increased until in three participants IVIg and cyclophosphamide could be stopped after 13, 44 and 9 months. Two years after cessation of treatment two participants worsened. The third deteriorated 17 months after stopping treatment. Reinstatement of periodic IVIg infusions induced clinical remission. Side effects related to cyclophosphamide occurred. Two participants had haemorrhagic cystitis, one after 13 and one after 15 months of treatment with a mean daily dose of $125 \mathrm{mg} /$ day to $150 \mathrm{mg} /$ day. Their symptoms resolved on stopping the drug. Of these two par- ticipants, one developed persistent amenorrhoea after one year of treatment, while the other was found to have persistent azoospermia a few years later (personal communication). The other participants in this study, who needed a mean dose of only $25 \mathrm{mg}$ to $90 \mathrm{mg}$ a day of cyclophosphamide (the dose was not expressed in relation to body weight) to induce the required level of leucopenia, did not experience any side effects during therapy. However, one of them died of bladder carcinoma ten years after stopping cyclophosphamide (personal communication).

Azulay et al. reported a series of 18 people with MMN followed for a mean of 25.3 months who all received periodic IVIg (Azulay 1997). In six, treatment was deemed ineffective after three to seven courses of IVIg. Three of these people received intravenous cyclophosphamide $\left(1 \mathrm{~g} / \mathrm{m}^{2}\right)$ monthly. This was subsequently reduced because of the development of leucopenia after two to three months. Of these three people, one individual was assessed to have improved after six months of treatment. Two other people in the study received oral cyclophosphamide at $1 \mathrm{mg} / \mathrm{kg}$ to $1.5 \mathrm{mg} / \mathrm{kg}$ and in one the frequency of IVIg could be reduced. The other person stopped responding to IVIg after three doses and oral cyclophosphamide had apparently no effect on the clinical course. Two important differences between the Meucci and Azulay studies may explain the difference in response to cyclophosphamide. First, in the Meucci study the cyclophosphamide dose was adjusted to achieve a predetermined white cell count ensuring that adequate immunosuppression was achieved. Second, in the Meucci study, all the cases had responded to an initial course of IVIg. In Azulay's series, three of the five people with MMN who were given cyclophosphamide had not responded to IVIg. However, EstradaAcosta et al. reported three people with MMN who responded to intravenous cyclophosphamide followed by six months of oral cyclophosphamide, $100 \mathrm{mg} /$ day, after not responding to IVIg, azathioprine and prednisolone and, in one person, to plasma exchange (Estrada-Acosta 1999), perhaps supporting the importance of adequate dose rather than IVIg-responsiveness in determining efficacy of cyclophosphamide.

In the retrospective series of 40 people with $M M N$, with a mean follow-up of $2.2+/-2.0$ years, reported by Léger et al. (Léger 2008), eight people (22\%) had significant remission (defined by no current therapy for at least six months), whereas 25 (68\%) were dependent on periodic IVIg infusions, of whom eight were given additional immunosuppressive agents, mainly cyclophosphamide and azathioprine.

Terenghi et al. (Terenghi 2004) treated seven people with repeated courses of IVIg and oral cyclophosphamide, one person receiving azathioprine and chlorambucil in addition. These individuals were followed for between five and 12 years. After a period of good response, almost all those treated experienced a deterioration in strength. This was most evident after six to eight years. This clinical worsening was associated with reduction in mean distal CMAP amplitude in examined nerves, suggesting that the treatment regimen might not have been very effective in reducing ax- 
onal degeneration.

In a person with MMN who was refractory to IVIg, high dose cyclophosphamide, $50 \mathrm{mg} / \mathrm{kg}$ for four days without stem cell rescue was able to induce remission. IVIg was discontinued and at six months the individual's strength improved and she regained the ability to write (Brannagan 2006).

An adverse effect from cyclophosphamide followed by autologous blood stem cell transplantation was reported in one person. He had been dependent on IVIg every four weeks and was treated with high dose intravenous cyclophosphamide followed by autologous blood stem cell transplantation. He deteriorated dramatically but recovered when IVIg was re-instituted (Axelson 2008).

\section{Rituximab}

In a report of two people given intravenous rituximab $375 \mathrm{mg} / \mathrm{m}^{2}$ for four weeks, one achieved the primary end point of a reduction in total IVIg dose by more than $25 \%$, while in the other the IVIg dose increased (Gorson 2007). In another report, one person, who was becoming less responsive to IVIg and not responding to or not tolerating adjunctive therapy with cyclophosphamide and interferon beta-1a, annual courses of rituximab $(375 \mathrm{mg} / \mathrm{m}$ 2 weekly for four weeks) for five years extended the interval of IVIg administration from seven to 12 days. This corresponded to a $42 \%$ reduction of IVIg (Ruegg 2004).

In an open label trial recently reported by Chaudhry 2011, six people with MMN on periodic IVIg treatments received two doses of rituximab $1000 \mathrm{mg}$ two weeks apart. The amount of IVIg used during the 12-month study period did not decrease when compared to the previous 12 months. There was also no change in MRC sum score, grip strength, overall disability sum score or the Rotterdam handicap scale. Four people reported subjective improvement but one worsened and one remained unchanged. Other than one person who developed hypersensitivity, rituximab was well tolerated.

\section{Azathioprine}

Oral azathioprine $(150 \mathrm{mg} / \mathrm{day}$ for ten months then reduced to $100 \mathrm{mg} /$ day up to 14 months) was reported to slightly delay disease exacerbation and consequent IVIg infusion (Toscano 2002). In Gutiérrez Ronquillo 2001, two out of five people with MMN improved and one stabilized after a course of IVIg followed by prednisone $60 \mathrm{mg} /$ day for three months and azathioprine $50 \mathrm{mg} /$ day for 12 months.

\section{Methotrexate}

Eight people who had responded to IVIg and were clinically stable on maintenance therapy received methotrexate (MTX) to reduce IVIg dosage and improve strength (Nobile-Orazio 2009). MTX was started at $7.5 \mathrm{mg}$ per week and increased to $10 \mathrm{mg}$ and then 15 $\mathrm{mg}$ at four weekly intervals. After four months of combined IVIg and MTX treatment, the IVIg dose of those who were stable or improving was reduced by $10 \%$ to $15 \%$ every two to three courses. If there was clinical deterioration, the dose was reverted to the last effective or starting dose. After a mean follow-up duration of 12.6 (range four to 18) months, three people continued MTX: one could stop IVIg completely, one was able to reduce IVIg by $30 \%$ and a third had subjective improvement (although disability scores did not change significantly). Three people stopped MTX because of side effects (dyspnoea and gastrointestinal). One of these three had a $50 \%$ reduction in IVIg dose while on treatment.

\section{Interferon beta}

Three people with MMN who had been receiving IVIg at intervals of two to six weeks for an average of six years were given subcutaneous interferon beta-1a $44 \mu \mathrm{g}$ three times a week for six months (Radziwill 2009). Two of them could increase the IVIg infusion interval by two weeks. No change was seen in disability scores, quality of life, electrophysiological parameters or cost. The authors report that none of the individuals treated elected to continue treatment beyond the study period due to "mild side effects and modest benefits".

\section{Eculizumab}

Fitzpatrick at al. published an open label study of 13 people with MMN using a monoclonal antibody, eculizumab, that prevents cleavage of $\mathrm{C} 5$ and thus inhibits terminal complement activation (Fitzpatrick 2011). Intravenous eculizumab $600 \mathrm{mg}$ was given at weeks zero, one, two and three, then $900 \mathrm{mg}$ every two weeks up to week 12 (five doses). Intravenous immunoglobulin was administered regularly to 10 participants if they worsened to a predetermined deterioration point. The primary outcome was safety, as assessed by the occurrence of adverse events during treatment and compared to the run-in period. Secondary outcomes were change in IVIg dosing frequency and change in multiple clinical and functional efficacy measurements at 4, 8 and 14 weeks. Electrophysiological parameters at baseline were compared with those at week 14 .

Eculizimab was generally well tolerated. The most common reported adverse event was headache, occurring largely in the first four weeks of treatment. Respiratory symptoms, musculoskeletal complaints and rash occurred less frequently. No patient developed a bacterial infection and none experienced worsening of MMN. There was no change in dosing frequency in nine of the 10 participants getting regular IVIg. One participant did not need IVIg during the treatment period. There were no significant differences in MRC sum score, but the sum of strength measured with a myometer in five muscles improved significantly. A self rated functional score improved significantly at week eight and 14 compared to baseline. A significant but small (6.5\%) decrease in conduction block was detected. 
Although this study demonstrated the short-term safety of eculizumab use with IVIg, evidence for efficacy was limited to some of the efficacy outcome measures and there was no significant reduction in requirement for IVIg. This result may have been biased by the lack of randomisation and consequent absence of blinding.

\section{Comparison of non-randomised evidence}

Overall, our non-systematic review of the various uncontrolled studies on the adjunctive use of immunosuppressants for the treatment of MMN suggests a moderate beneficial effect of cyclophosphamide. It may be more efficacious in participants who have responded to IVIg. A RCT would be needed to establish whether the suggested benefit is real. Before such a trial were undertaken, the known harms produced by cyclophosphamide would require careful consideration. The use of corticosteroids, and occasionally plasma exchange, has been associated with deterioration. The role of less toxic cytotoxic agents, such as azathioprine, interferon beta, ciclosporin, rituximab and methotrexate has not been adequately explored.

\section{Potential biases in the review process}

MMN is a rare disease and the authors are likely to have known about all randomised trials conducted or being conducted in the field. The unavoidable weaknesses of the review are the dearth of randomised trials and lack of large enough observational studies to permit reliable conclusions. Even the one trial identified was too small to identify or exclude even moderate benefit or harm.

\section{General discussion}

In conclusion, the data from a mixture of controlled trials, case series and anecdotal experience have established IVIg as the firstline treatment for MMN. A Cochrane systematic review agreed with this conclusion (van Schaik 2005). One study that suggested benefit from mycophenolate mofetil (Benedetti 2004) was not supported by a subsequent RCT (Piepers 2007), which did not show significant benefit in strength or function. The observational data concerning other immunosuppressive agents have to be interpreted with caution, because of publication bias and the wide variability of clinical course and IVIg responsiveness of MMN (Azulay 1997; Slee 2007; Taylor 2000; Terenghi 2004; van den Berg 1998; Vucic 2004). The occurrence of MMN-like illness in people taking infliximab, the worsening of some individuals while on corticosteroids and our limited understanding of the pathogenesis of MMN make it difficult to predict its response to novel immunomodulatory agents. These factors magnify the need for RCTs despite the logistical challenges.

Additional issues that need to be addressed in controlled studies are:
(1) What is the best option for people with MMN who do not respond to IVIg? A RCT of cyclophosphamide should be considered for severely affected people with MMN. The severity of disability in such refractory cases may justify the use of a relatively toxic medication such as cyclophosphamide. Less toxic drugs such as azathioprine, ciclosporin, methotrexate or rituximab could be studied in less severely affected individuals.

(2) For people with MMN who lose their responsiveness or require frequent IVIg infusions, the adjunctive therapeutic role of drugs other than mycophenolate mofetil should be explored. Such treatment regimens should be designed to reduce the slow neurological deterioration that is seen in some people treated with regular IVIg infusions (Taylor 2000; Terenghi 2004; van den Berg 1998; van den Berg-Vos 2002).

(3) Studies to identify factors that predict lack or gradual loss of response to IVIg (van den Berg-Vos 2000c; Vucic 2004) would be useful in selecting people relatively early for alternative and combination treatment regimens, before axonal damage precludes significant recovery.

(4) More research is needed to identify the best outcomes to measure in multicentre trials of treatment for MMN. The self evaluation scale used in the Piepers 2007 trial has good face validity but requires comparison with other scales and testing for reproducibility and responsiveness. Other existing scales might be superior but new more responsive scales might need to be developed to increase the power of MMN treatment trials. The correlation between resolution of conduction block and clinical response to treatment has varied in different studies (Federico 2000; Léger 2001; Léger 2008). Alternative responsive electrodiagnostic outcome measures would be helpful. An international workshop has proposed a Rasch derived disability outcome scale as the preferred primary outcome measure (Vanhoutte 2013). The workshop also recommended a Rasch transformed MRC scale, strength measured with a dynamometer (especially of muscle groups relevant to the individual) and Rasch transformed Quality of Life scales as secondary outcome measures.

\section{A U THORS'CONCLUSIONS}

\section{Implications for practice}

According to moderate quality evidence from the only randomised controlled trial of an immunosuppressive agent in multifocal motor neuropathy, mycophenolate mofetil did not significantly improve strength or function or reduce the need for intravenous immunoglobulin.

\section{Implications for research}

Randomised controlled trials are needed of cyclophosphamide for severe disease, and less toxic agents, other than mycophenolate 
mofetil, for moderate or mild disease, to reduce the need for intravenous immunoglobulin in people who respond to it and to treat people who do not respond. The scales for measuring disability in multifocal motor neuropathy need to be optimised.

\section{ACKNOWLEDGEMENTS}

The Cochrane Neuromuscular Disease Group Trials Search Coordinator developed search strategies and performed most of the database searches. We thank the Cochrane Neuromuscular Disease Group Managing Editor for her careful editing of the text.

\section{REFER E N C ES}

\section{References to studies included in this review}

Piepers 2007 \{published and unpublished data\}

Piepers S, van den Berg-Vos R, van der Pol WL, Franssen $\mathrm{H}$, Wokke J, van den Berg L. Mycophenolate mofetil as adjunctive therapy for MMN patients: a randomized, controlled trial. Brain 2007;130(Pt 8):2004-10.

[PUBMED: 17626040]

\section{Additional references}

\section{Abbruzzese 1997}

Abbruzzese M, Reni L, Schenone A, Mancardi GL Primavera A. Multifocal motor neuropathy with conduction block after Campylobacter jejuni enteritis. Neurology 1997; 48(2): 544 .

Allison 2000

Allison AC, Eugui EM. Mycophenolate mofetil and its mechanisms of action. Immunopharmacology 2000;47(2-3): $85-118$.

Axelson 2008

Axelson HW, Oberg G, Askmark H. No benefit of treatment with cyclophosphamide and autologous blood stem cell transplantation in multifocal motor neuropathy. Acta Neurologica Scandinavica 2008;117(6):432-4.

\section{Azulay 1994}

Azulay JP, Blin O, Pouget J, Boucraut J, Bille-Turc F, Carles $\mathrm{G}$, et al. Intravenous immunoglobulin treatment in patients with motor neuron syndromes associated with antiGM1 antibodies: a double-blind, placebo-controlled study. Neurology 1994;44(3 Pt 1):429-32.

Azulay 1997

Azulay JP, Rihet P, Pouget J, Cador F, Blin O, Boucraut J, et al. Long term follow up of multifocal motor neuropathy with conduction block under treatment. Journal of Neurology, Neurosurgery and Psychiatry 1997;62(4):391-4.

\section{Benedetti 2004}

Benedetti L, Grandis M, Nobbio L, Beronio A, Ghiglione E, Manzino M, et al. Mycophenolate mofetil in dysimmune neuropathies: a preliminary study. Muscle \& Nerve 2004;29 (5):748-9.

Bentes 1999

Bentes C, Carvalho M, Evangelista T, Sales-Luis ML. Multifocal motor neuropathy mimicking motor neuron disease: nine cases. Journal of the Neurological Sciences 1999; 169(1-2):76-9.

\section{Beydoun 1998}

Beydoun SR. Multifocal motor neuropathy with conduction block misdiagnosed as multiple entrapment neuropathies. Muscle \& Nerve 1998;21(6):813-5.

Beydoun 2000

Beydoun SR, Copeland D. Bilateral phrenic neuropathy as a presenting feature of multifocal motor neuropathy with conduction block. Muscle \& Nerve 2000;23(4):556-9.

Bouche 1995

Bouche P, Moulonguet A, Younes-Chennoufi AB, Adams $D$, Baumann N, Meininger $V$, et al. Multifocal motor neuropathy with conduction block: a study of 24 patients. Journal of Neurology, Neurosurgery and Psychiatry 1995;59 (1):38-44.

\section{Brannagan 2006}

Brannagan TH 3rd, Alaedini A, Gladstone DE. High-dose cyclophosphamide without stem cell rescue for refractory multifocal motor neuropathy. Muscle \& Nerve 2006;34(2): 246-50.

\section{Carpo 1998}

Carpo M, Cappellari A, Mora G, Pedotti R, Barbieri S, Scarlato G, et al. Deterioration of multifocal motor neuropathy after plasma exchange. Neurology 1998;50(5): $1480-2$.

Cats 2010 Cats EA, van der Pol WL, Piepers S, Franssen H, Jacobs BC, van den Berg-Vos RM, et al. Correlates of outcome and response to IVIg in 88 patients with multifocal motor neuropathy. Neurology 2010;75(9):818-25. 


\section{Chad 1986}

Chad DA, Hammer K, Sargent J. Slow resolution of multifocal weakness and fasciculation: a reversible motor neuron syndrome. Neurology 1986;36(9):1260-3.

\section{Charles 1992}

Charles N, Benoit P, Vial C, Bierme T, Moreau T, Bady B. Intravenous immunoglobulin treatment in multifocal motor neuropathy. Lancet 1992;340(8812):182.

\section{Chaudhry 1993}

Chaudhry V, Corse AM, Cornblath DR, Kuncl RW, Drachman DB, Freimer ML, et al. Multifocal motor neuropathy: response to human immune globulin. Annals of Neurology 1993;33(3):237-42.

\section{Chaudhry 1996}

Chaudhry V, Corse AM, Cornblath DR, Kuncl RW, Adornato B, Miller R, et al. Maintenance immune globulin therapy for multifocal motor neuropathy: results of long term follow-up. Annals of Neurology 1996;40(3):513-4.

\section{Chaudhry 2001}

Chaudhry V, Cornblath DR, Griffin JW, O'Brien R, Drachman DB. Mycophenolate mofetil: a safe and promising immunosuppressant in neuromuscular diseases. Neurology 2001;56(1):94-6.

\section{Chaudhry 2006}

Chaudhry V, Swash M. Multifocal motor neuropathy: is conduction block essential?. Neurology 2006;67(4):558-9.

\section{Chaudhry 2011}

Chaudhry V, Cornblath DR. An open-label trial of rituximab (Rituxan ${ }^{\circledR}$ ) in multifocal motor neuropathy. Journal of the Peripheral Nervous System 2010;15(3): 196-201.

\section{Ciafaloni 200}

Ciafaloni E, Massey JM, Tucker-Lipscomb B, Sanders DB. Mycophenolate mofetil for myasthenia gravis: an openlabel pilot study. Neurology 2001;56(1):97-9.

\section{Cisternas 2002}

Cisternas M, Gutierrez M, Jacobelli S. Successful rechallenge with anti-tumor necrosis factor alpha for psoriatic arthritis after development of demyelinating nervous system disease during initial treatment: comment on the article by Mohan et al. Arthritis and Rheumatism 2002;46(11):3107-8.

\section{Claus 2000}

Claus D, Specht S, Zieschang M. Plasmapheresis in multifocal motor neuropathy: a case report. Journal of Neurology, Neurosurgery and Psychiatry 2000;68(4):533-5.

\section{Cocito 2005}

Cocito D, Bergamasco B, Tavella A, Poglio F, Paolasso I, Costa P, et al. Multifocal motor neuropathy during treatment with infliximab. Journal of the Peripheral Nervous System 2005;10(4):386-7.

\section{Comi 1994}

Comi G, Amadio S, Galardi G, Fazio R, Nemni R. Clinical and neurophysiological assessment of immunoglobulin therapy in five patients with multifocal motor neuropathy.
Journal of Neurology, Neurosurgery and Psychiatry 1994;57

Suppl:35-7.

\section{Cornblath 1991}

Cornblath DR, Sumner AJ, Daube J, Gilliat RW, Brown WF, Parry GJ, et al. Conduction block in clinical practice. Muscle \& Nerve 1991;14(9):869-71.

\section{Corse 1996}

Corse AM, Chaudhry V, Crawford TO, Cornblath DR, Kuncl RW, Griffin JW. Sensory nerve pathology in multifocal motor neuropathy. Annals of Neurology 1996;39 (3):319-25.

\section{Cruz 1993}

Cruz Martinez A, Arpa J, Lara M. Electrophysiological improvement after intravenous immunoglobulin in motor neuropathy with multifocal conduction block [letter]. Journal of Neurology, Neurosurgery and Psychiatry 1993;56 (11):1236-7.

de Carvalho 1997

de Carvalho M, Luis ML. Relapsing chronic low-dose corticosteroid responsive multifocal motor neuropathy with conduction block. Electromyography and Clinical Neurophysiology 1997;37(2):95-7.

Delmont 2006

Delmont E, Azulay JP, Giorgi R, Attarian S, Verschueren A, Uzenot D, et al. Multifocal motor neuropathy with and without conduction block: a single entity?. Neurology 2006 67(4):592-6.

\section{Donaghy 1994}

Donaghy M, Mills KR, Boniface SJ, Simmons J, Wright I, Gregson N, et al. Pure motor demyelinating neuropathy: deterioration after steroid treatment and improvement with intravenous immunoglobulin. Journal of Neurology, Neurosurgery and Psychiatry 1994;57(7):778-83.

\section{ENMC 2001}

Hughes R. 79th ENMC International Workshop: Multifocal motor neuropathy, 14-15 April 2000, Hilversum, The Netherlands. Neuromuscular Disorders 2001;11: 309-14.

\section{Estrada-Acosta 1999}

Estrada-Acosta R, Lestayo-O'Farrill Z, Coba-Morales C. Multifocal motor neuropathy with block of nerve conduction. Report of three cases. Revista de Neurologica 1999;29(2):130-3.

Fardet 2007

Fardet L, Dupuy A, Kerob D, Levy A, Allez M, Begon E, et al. Infliximab for severe hidradenitis suppurativa: transient clinical efficacy in 7 consecutive patients. Journal of the American Academy of Dermatology 2007;56(4):624-8.

Federico 2000

Federico P, Zochodne DW, Hahn AF, Brown WF, Feasby TE. Multifocal motor neuropathy improved by IVIg: randomized, double-blind, placebo-controlled study. Neurology 2000;55(9):1256-62. 


\section{Feldman 1991}

Feldman EL, Bromberg MB, Albers JW, Pestronk A. Immunosuppressive treatment in multifocal motor neuropathy. Annals of Neurology 1991;30(3):397-401.

Finsterer 1999

Finsterer J, Schwerer B, Bittner RE, Mamoli B. Cerebrospinal fluid filtration and immunoglobulins in multifocal motor neuropathy. Clinical Neuropathology 1999;18(1):31-6.

\section{Finsterer 1999a}

Finsterer J, Derfler K. Immunoadsorption in multifocal motor neuropathy. Journal of Immunotherapy 1999;22(5): $441-2$.

\section{Fitzpatrick 2011}

Fitzpatrick AM, Mann CA, Barry S, Brennan K, Overell JR, Willison HJ. An open label clinical trial of complement inhibition in multifocal motor neuropathy. Journal of the Peripheral Nervous System 2011;16(2):84-91.

\section{Gorson 1999}

Gorson KC, Ropper AH, Weinberg DH. Upper limb predominant, multifocal chronic inflammatory demyelinating polyneuropathy. Muscle \& Nerve 1999;22 (6):758-65.

\section{Gorson 2007}

Gorson KC, Natarajan N, Ropper AH, Weinstein R. Rituximab treatment in patients with IVIg-dependent immune polyneuropathy: a prospective pilot trial. Muscle \& Nerve 2007;35(1):66-9.

\section{GRADEpro 2014}

GRADEpro. [Computer program on www.gradepro.org]. Version 2014. McMaster University 2014.

\section{Gutiérrez Ronquillo 2001}

Gutiérrez Ronquillo JH, Andrade Machado R, Machado Rojas A, Garcia Espinosa A. Multifocal motor neuropathy with partial nerve conduction. Revista de Neurologia 2001; 32(5):427-30.

\section{Halloran 1997}

Halloran P, Mathew T, Tomlanovich S, Groth C, Hooftman $\mathrm{L}$, Barker C. Mycophenolate mofetil in renal allograft recipients: a pooled efficacy analysis of three randomized, double-blind, clinical studies in prevention of rejection. The International Mycophenolate Mofetil Renal Transplant Study Groups. Transplantation 1997;63(1):39-47.

Hausmanowa-Petrusewicz 1991

Hausmanowa-Petrusewicz I, Rowiń ska-Marciń ska K, Kope ć A. Chronic acquired demyelinating motor neuropathy. Acta Neurologica Scandinavica 1991;84(1):40-5.

Higgins 2003

Higgins JPT, Thompson SG, Deeks JJ, Altman DG. Measuring inconsistency in meta-analyses. BMJ 2003;327 (7414):557-60.

Higgins 2011

Higgins JPT, Green S (editors). Cochrane Handbook for Systematic Reviews of Interventions Version 5.1.0 [updated March 2011]. The Cochrane Collaboration, 2011. Available from www.cochrane-handbook.org.

\section{Hoang-Xuan 1993}

Hoang-Xuan K, Léger JM, Ben Younes-Chennoufi A, Saidi H, Bouche P, Baumann N, et al. Treatment of immune deficient neuropathies with intravenous polyvalent immunoglobulins. An open study of 16 cases. Revue Neurologique 1993;149(6-7):385-92.

\section{Jarrett 2003}

Jarrett SJ, Cunnane G, Conaghan PG, Bingham SJ, Buch $\mathrm{MH}$, Quinn MA, et al. Anti-tumor necrosis factoralpha therapy-induced vasculitis: case series. Journal of Rheumatology 2003;30(10):2287-91.

\section{Jaspert 1996}

Jaspert A, Claus D, Grehl H, Neundorfer B. Multifocal motor neuropathy: clinical and electrophysiological findings. Journal of Neurology 1996;243(10):684-92.

Kaji 1992

Kaji R, Shibasaki H, Kimura J. Multifocal demyelinating motor neuropathy: cranial nerve involvement and immunoglobulin therapy. Neurology 1992;42(3 Pt 1): 506-9.

Kaji 1993

Kaji R, Oka N, Tsuji T, Mezaki T, Nishio T, Akiguchi I, et al. Pathological findings at the site of conduction block in multifocal motor neuropathy. Annals of Neurology 1993;33 (2):152-8.

\section{Kleyweg 1991}

Kleyweg RP, van der Meché FG, Schmitz PI. Interobserver agreement in the assessment of muscle strength and functional abilities in Guillain-Barré syndrome. Muscle \& Nerve 1991;14(11):1103-9.

\section{Komiyama 1998}

Komiyama A, Toda H, Hasegawa O, Kuroiwa Y. Multifocal motor neuropathy. Neurology 1998;50(1):314.

\section{Kornberg 1994}

Kornberg AJ, Pestronk A. The clinical and diagnostic role of anti-GM1 antibody testing. Muscle \& Nerve 1994;17(1): $100-4$.

Kosa 2009

Kosa S, Klein CJ. Infliximab associated motor neuropathy typically has monophasic improving course with drug discontinuation. Neurology 2009;72:A264.

\section{Krarup 1990}

Krarup C, Stewart JD, Sumner AJ, Pestronk A, Lipton SA. A syndrome of asymmetric limb weakness with motor conduction block. Neurology 1990;40(1):118-27.

\section{Lange 1992}

Lange DJ, Trojaborg W, Latov N, Hays AP, Younger DS, Uncini A, et al. Multifocal motor neuropathy with conduction block: is it a distinct clinical entity?. Neurology 1992;42(3 Pt 1):497-505.

\section{Le Forestier 1997}

Le Forestier N, Chassande B, Moulonguet A, Masionobe T, Schaeffer S, Birouk N, et al. Multifocal motor neuropathy 
with conduction block: 39 cases. Revue Neurologique 1997; 153(10):579-86.

\section{Lehmann 2008}

Lehmann HC, Hoffmann FR, Fusshoeller A, Meyer zu Horste G, Hetzel R, Hartung HP, et al. The clinical value of therapeutic plasma exchange in multifocal motor neuropathy. Journal of the Neurological Sciences 2008;271 (1-2):34-9.

\section{Lewis 1982}

Lewis RA, Sumner AJ, Brown MJ, Asbury AK. Multifocal demyelinating neuropathy with persistent conduction block. Neurology 1982;32(9):958-64.

\section{Lewis 1999}

Lewis RA. Multifocal motor neuropathy and Lewis Sumner syndrome: two distinct entities [letter; comment]. Muscle \& Nerve 1999;22(12):1738-9.

\section{Lozeron 2009}

Lozeron P, Denier C, Lacroix C, Adams D. Long-term course of demyelinating neuropathies occurring during tumor necrosis factor-alpha-blocker therapy. Archives of Neurology 2009;66(4):490-7.

\section{Léger 1994}

Léger JM, Younes-Chennoufi AB, Chassande B, Davila G, Bouche P, Baumann N, et al. Human immunoglobulin treatment of multifocal motor neuropathy and polyneuropathy associated with monoclonal gammopathy. Journal of Neurology, Neurosurgery and Psychiatry 1994; November 57 Suppl:46-9.

\section{Léger 2001}

Léger JM, Chassande B, Musset L, Meininger V, Bouche $\mathrm{P}$, Baumann N. Intravenous immunoglobulin therapy in multifocal motor neuropathy: A double-blind, placebocontrolled study. Brain 2001;124(Pt 1):145-53.

\section{Léger 2008}

Léger JM, Viala K, Cancalon F, Maisonobe T, Gruwez B, Waegemans $\mathrm{T}$, et al. Intravenous immunoglobulin as shortand long-term therapy of multifocal motor neuropathy: a retrospective study of response to IVIg and of its predictive criteria in 40 patients. Journal of Neurology, Neurosurgery and Psychiatry 2008;79(1):93-6.

\section{Martina 1999}

Martina IS, van Doorn PA, Schmitz PI, Meulstee J, van der Meché FG. Chronic motor neuropathies: response to interferon-beta1a after failure of conventional therapies. Journal of Neurology, Neurosurgery and Psychiatry 1999;66 (2):197-201.

\section{Meriggioli 2003}

Meriggioli MN, Rowin J, Richman JG, Leurgans S. Mycophenolate mofetil for myasthenia gravis: a doubleblind, placebo-controlled pilot study. Annals of the New York Academy of Sciences 2003;998:494-9.

\section{Meucci 1997}

Meucci N, Cappellari A, Barbieri S, Scarlato G, NobileOrazio E. Long term effect of intravenous immunoglobulins and oral cyclophosphamide in multifocal motor neuropathy.
Journal of Neurology, Neurosurgery and Psychiatry 1997;63 (6):765-9.

Mezaki 1999

Mezaki T, Kaji R, Kimura J. Multifocal motor neuropathy and Lewis Sumner syndrome: a clinical spectrum. Muscle \& Nerve 1999;22(12):1739-40.

\section{Michaud 2011}

Michaud A, Delmont E, Jeandel PY, Desnuelle C. [Improvement of severe and intravenous immunoglobulindependent multifocal motor neuropathy with conduction block after long-term rituximab]. Revue Neurologique (Paris) 2011;167(12):916-20.

\section{Mowzoon 2001}

Mowzoon N, Sussman A, Bradley WG. Mycophenolate (CellCept) treatment of myasthenia gravis, chronic inflammatory polyneuropathy and inclusion body myositis. Journal of the Neurological Sciences 2001;185(2):119-22.

\section{Nemni 2003}

Nemni R, Santuccio G, Calabrese E, Galardi G, Canal N. Efficacy of cyclosporine in multifocal motor neuropathy. Journal of Neurology 2003;250(9):1118-20.

\section{Nobile-Orazio 1993}

Nobile-Orazio E, Meucci N, Barbieri S, Carpo M, Scarlato G. High-dose intravenous immunoglobulin therapy in multifocal motor neuropathy. Neurology 1993;43(3 Pt 1): 537-44.

\section{Nobile-Orazio 2001}

Nobile-Orazio E. Multifocal motor neuropathy. Journal of Neuroimmunology 2001;115(1-2):4-18.

\section{Nobile-Orazio 2002}

Nobile-Orazio E, Cappellari A, Meucci N, Carpo M, Terenghi F, Bersano A, et al. Multifocal motor neuropathy: clinical and immunological features and response to IVIg in relation to the presence and degree of motor conduction block. Journal of Neurology, Neurosurgery and Psychiatry 2002;72(6):761-6.

\section{Nobile-Orazio 2009}

Nobile-Orazio E, Terenghi F, Cocito D, Gallia F, Casellato C. Oral methotrexate as adjunctive therapy in patients with multifocal motor neuropathy on chronic IVIg therapy. Journal of the Peripheral Nervous System 2009;14(3):203-5.

Oh 1997

Oh SJ, Claussen GC, Kim DS. Motor and sensory demyelinating mononeuropathy multiplex (multifocal motor and sensory demyelinating neuropathy): a separate entity or a variant of chronic inflammatory demyelinating polyneuropathy?. Journal of the Peripheral Nervous System 1997;2(4):362-9.

\section{Oh 2000}

Oh SJ. Multifocal inflammatory demyelinating neuropathy: A distinct clinical entity?. Neurology 2000;55(5):735-42.

\section{Olney 2003}

Olney RK, Lewis RA, Putnam TD, Campellone JV Jr. American Association of Electrodiagnostic Medicine. 
Consensus criteria for the diagnosis of multifocal motor neuropathy. Muscle and Nerve 2003;27(1):117-21.

\section{Oxford 2003}

Oxford Grice K, Vogel KA, Le V, Mitchell A, Muniz S, Vollmer MA. Adult norms for a commercially available Nine Hole Peg Test for finger dexterity. American Journal of Occupational Therapy 2003;57(5):570-3.

\section{Pakiam 1998}

Pakiam AS, Parry GJ. Multifocal motor neuropathy without overt conduction block. Muscle and Nerve 1998;21(2): 243-5.

Parry 1985

Parry GJ, Clarke S. Pure motor neuropathy with multifocal conduction block masquerading as motor neuron disease. Muscle and Nerve 1985;8(6):167 (abstract).

Parry 1988

Parry GJ, Clarke S. Multifocal acquired demyelinating neuropathy masquerading as motor neuron disease. Muscle and Nerve 1988;11(2):103-7.

Pestronk 1988

Pestronk A, Cornblath DR, Ilyas AA, Baba H, Quarles RH, Griffin JW, et al. A treatable multifocal motor neuropathy with antibodies to GM1 ganglioside. Annals of Neurology 1988;24(1):73-8.

Pestronk 1990

Pestronk A, Chaudhry V, Feldman EL, Griffin JW, Cornblath DR, Denys EH, et al. Lower motor neuron syndromes defined by patterns of weakness, nerve conduction abnormalities, and high titers of anti-glycolipid antibodies. Annals of Neurology 1990;27(3):316-26.

\section{Pestronk 2002}

Pestronk A. Neuromuscular Disease Center,

Washington University School of Medicine. http:// www.neuro.wustl.edu/neuromuscular.

\section{Pestronk 2003}

Pestronk A, Florence J, Miller T, Choksi, Al-Lozi MT, Levine TD. Treatment of IgM antibody associated polyneuropathies using rituximab. Journal of Neurology, Neurosurgery and Psychiatry 2003;74(4):485-9.

\section{Pisoni 2007}

Pisoni CN, Cuadrado MJ, Khamashta MA, Hughes GR, D'Cruz DP. Mycophenolate mofetil treatment in resistant myositis. Rheumatology (Oxford) 2007;46(3):516-8.

Pringle 1997

Pringle CE, Belden MD, Veitch JE, Brown WF. Multifocal motor neuropathy presenting as ophthalmoplegia. Muscle \& Nerve 1997;20(3):347-51.

\section{Radziwill 2006}

Radziwill AJ, Schweikert K, Kuntzer T, Fuhr P, Steck AJ. Mycophenolate mofetil for chronic inflammatory demyelinating polyradiculoneuropathy: An open-label study. European Neurology 2006;56(1):37-8.

\section{Radziwill 2009}

Radziwill AJ, Botez SA, Novy J, Kuntzer T. Interferon beta$1 \mathrm{a}$ as adjunctive treatment for multifocal motor neuropathy: an open label trial. Journal of the Peripheral Nervous System 2009;14(3):201-2.

RevMan 2014

The Nordic Cochrane Centre, The Cochrane Collaboration. Review Manager (RevMan). 5.3. Copenhagen: The Nordic Cochrane Centre, The Cochrane Collaboration, 2014.

\section{Rhee 1990}

Rhee EK, England JD, Sumner AJ. A computer simulation of conduction block: effects produced by actual block versus interphase cancellation. Annals of Neurology 1990;28 (2):146-56

\section{Richette 2004}

Richette P, Dieude P, Damiano J, Liote F, Orcel P, Bardin T. Sensory neuropathy revealing necrotizing vasculitis during infliximab therapy for rheumatoid arthritis. Journal of Rheumatology 2004;31 (10):2079-81.

\section{Richez 2005}

Richez C, Blanco P, Lagueny A, Schaeverbeke T, Dehais J. Neuropathy resembling CIDP in patients receiving tumor necrosis factor-alpha blockers. Neurology 2005;64(8): $1468-70$.

\section{Rodriguez-Escalera 2005}

Rodriguez-Escalera C, Belzunegui J, Lopez-Dominguez L, Gonzalez C, Figueroa M. Multifocal motor neuropathy with conduction block in a patient with rheumatoid arthritis on infliximab therapy. Rheumatology (Oxford) 2005;44(1): 132-3.

\section{Rojas-Garcia 2003}

Rojas-Garcia R, Gallardo E, de Andres I, de Luna N, Juarez C, Sanchez P, et al. Chronic neuropathy with IgM anti-ganglioside antibodies:lack of response to rituximab. Neurology 2003;61(12):1814-6. [PUBMED: 14694058]

\section{Ronquillo 2001}

Gutierrez Ronquillo JH, Andrade Machado R, Machado Rojas A, Garcia Espinosa A. Multifocal motor neuropathy with partial block nerve conduction. Revista de Neurologica 2001;32(5):427-430.

\section{Roth 1986}

Roth G, Rohr J, Magistris MR, Ochsner F. Motor neuropathy with proximal multifocal persistent conduction block, fasciculations and myokymia. European Journal of Neurology 1986;25(6):416-23.

\section{Ruegg 2004}

Ruegg SJ, Fuhr P, Steck AJ. Rituximab stabilizes multifocal motor neuropathy increasingly less responsive to IVIg. Neurology 2004;63(11):2178-9.

\section{Sanders 2008}

Sanders DB, Hart IK, Mantegazza R, Shukla SS, Siddiqi ZA, de Baets $\mathrm{MH}$, et al. An international, phase III, randomized trial of mycophenolate mofetil in myasthenia gravis. Neurology 2008;71(6):400-6. [PUBMED: 18434638 ]

\section{Saperstein 1999}

Saperstein DS, Amato AA, Wolfe GI, Katz JS, Nations SP, Jackson CE, et al. Multifocal acquired demyelinating 
sensory and motor neuropathy: the Lewis-Sumner syndrome. Muscle \& Nerve 1999;22(5):560-6.

\section{Sharrack 1999}

Sharrack B, Hughes RAC. The Guy's Neurological Disability Rating Scale (GNDS): a new disability measure for multiple sclerosis. Multiple Sclerosis 1999;5(4):223-33.

Singer 2004

Singer OC, Otto B, Steinmetz H, Ziemann U. Acute neuropathy with multiple conduction blocks after TNFalpha monoclonal antibody therapy. Neurology 2004; 63(9): 1754

Slee 2007

Slee M, Selvan A, Donaghy M. Multifocal motor neuropathy: the diagnostic spectrum and response to treatment. Neurology 2007;69(17):1680-7.

Stieglbauer 2009

Stieglbauer K, Topakian R, Hinterberger G, Aichner FT. Beneficial effect of rituximab monotherapy in multifocal motor neuropathy. Neuromuscular Disorders 2009;19(7): 473-5.

\section{Tan 1994}

Tan E, Lynn J, Amato AA, Kissel JT, Rammohan KW, Sahenk Z, et al. Immunosuppressive treatment of motor neuron syndromes. Attempts to distinguish treatable disease. Archives of Neurology 1994;51(2):194-200.

Taylor 1996

Taylor BV, Gross L, Windebank AJ. The sensitivity and specificity of anti-GM1 antibody testing. Neurology 1996; 47(1):951-5.

\section{Taylor 2000}

Taylor BV, Wright RA, Harper CM, Dyck PJ. Natural history of 46 patients with multifocal motor neuropathy with conduction block. Muscle and Nerve 2000;23(6): $900-8$.

\section{Tektonidou 2007}

Tektonidou MG, Serelis J, Skopouli FN. Peripheral neuropathy in two patients with rheumatoid arthritis receiving infliximab treatment. Clinical Rheumatology 2007; 26(2):258-60.

Terenghi 2004

Terenghi F, Cappellari A, Bersano A, Carpo M, Barbieri S, Nobile-Orazio E. How long is IVIg effective in multifocal motor neuropathy?. Neurology 2004;62(4):666-8.

\section{Terenghi 2006}

Terenghi F, Allaria S, Nobile-Orazio E. Circulating levels of cytokines and their modulation by intravenous immunoglobulin in multifocal motor neuropathy. Journal of the Peripheral Nervous System 2006;11(1):67-71.

Toscano 2002

Toscano A, Rodolico C, Benvenga S, Girlanda P, Laura M, Mazzeo A, et al. Multifocal motor neuropathy and asymptomatic Hashimoto's thyroiditis: first report of an association. Neuromuscular Disorders 2002;12(6):566-8.
Umapathi 2002

Umapathi T, Hughes R. Mycophenolate in treatmentresistant inflammatory neuropathies. European Journal of Neurology 2002;9(6):683-5.

\section{van Asseldonk 2006}

van Asseldonk JTH, van den Berg LH, Wieneke GH, Wokke JHJ. Criteria for conduction block based on computer simulation studies of nerve conduction with human data obtained in the forearm segment of the median nerve. Brain 2006;129(9):2447-60. [PUBMED: 16923956]

\section{van den Berg 1995}

van den Berg LH, Kerkhoff H, Oey PL, Franssen H, Mollee I, Vermeulen M, et al. Treatment of multifocal motor neuropathy with high dose intravenous immunoglobulins: a double blind, placebo controlled study. Journal of Neurology, Neurosurgery and Psychiatry 1995;59(3):248-52.

van den Berg 1997

van den Berg LH, Lokhorst H, Wokke JHJ. Pulsed highdose dexamethasone is not effective in patients with multifocal motor neuropathy. Neurology 1997;48(4):1135.

van den Berg 1998

van den Berg LH, Franssen H, Wokke JH. The longterm effect of intravenous immunoglobulin treatment in multifocal motor neuropathy. Brain 1998;121(Pt 3):421-8.

\section{van den Berg-Vos 2000a} van den Berg-Vos RM, van den Berg LH, Franssen H, Vermeulen M, Witkamp TD, Jansen GH, et al. Multifocal inflammatory demyelinating neuropathy: a distinct clinical entity?. Neurology 2000;54(1):26-32.

van den Berg-Vos 2000b van den Berg-Vos RM, van den Berg LH, Franssen H, van Doorn PA, Merkies IS, Wokke JH. Treatment of multifocal motor neuropathy with interferon-beta1a. Neurology 2000; 54(7):1518-21.

van den Berg-Vos 2000c

van den Berg-Vos RM, Franssen H, Wokke JH, van Es HW, van den Berg LH. Multifocal motor neuropathy: diagnostic criteria that predict the response to immunoglobulin treatment. Annals of Neurology 2000;48(6):919-26.

\section{van den Berg-Vos 2002}

van den Berg-Vos RM, Franssen H, Wokke JH, van den Berg LH. Multifocal motor neuropathy: long term clinical and electrophysiological assessment of intravenous immunoglobulin maintenance treatment. Brain 2002;125 (Pt 8):1875-86.

Van den Bergh 1989

Van den Bergh P, Logigian EL, Kelly JJ Jr. Motor neuropathy with multifocal conduction blocks. Muscle \& Nerve 1989;12(1):26-31.

van Es 1997

van Es HW, van den Berg LH, Franssen H, Witkamp TD, Ramos LM, Notermans NC, et al. Magnetic resonance imaging of the brachial plexus in patients with multifocal motor neuropathy. Neurology 1997;48(5):1218-24. 
van Schaik 2005

van Schaik IN, Vermeulen MM, de Haan R, van den Berg LH. Intravenous immunoglobulin for multifocal motor neuropathy. Cochrane Database of Systematic Reviews 2005, Issue 2. [DOI: 10.1002/14651858.CD004429.pub2]

van Schaik 2006

van Schaik I, Bouche P, Illa I, Leger JM, Van den Bergh P, Cornblath DR, et al. European Federation of Neurological Societies/Peripheral Nerve Society guideline on management of multifocal motor neuropathy. Journal of the Peripheral Nervous System 2006;13(8):802-8.

van Swieten 1988

van Swieten JC, Koudstaal PJ, Visser MC, Schouten HJA, van Gijn J. Interobserver agreement for assessment of handicap in stroke patients. Stroke 1988;19(5):604-7.

Vanhoutte 2013

Vanhoutte EK, Faber CG, Merkies IS, PeriNomS Study Group. 196th ENMC international workshop: outcome measures in inflammatory peripheral neuropathies 8-10 February 2013, Naarden, The Netherlands. Neuromuscular Disorders 2013;23(11):924-33.

\section{Viala 2004}

Viala K, Renie L, Maisonobe T, Behin A, Neil J, Leger JM, et al. Follow-up study and response to treatment in 23 patients with Lewis-Sumner syndrome. Brain 2004;127(Pt 9):2010-7.

\section{Vrethem 1996}

Vrethem M, Lindvall B, Kihlstrand S, Backman E, Brismar T, Fredman P, et al. High-dose intravenous immunoglobulin therapy improved muscle strength in a patient with multifocal motor neuropathy and antibodies against the gycolipid LK1. European Journal of Neurology 1996;3(2):156-9.

Vucic 2004

Vucic S, Black KR, Chong PST, Cros D. Multifocal motor neuropathy: decrease in conduction blocks and reinnvervation with long-term IVIg. Neurology 2004;63(7):

1264-9.

\section{Willison 1999}

Willison HG, Veitch J, Swan AV, Baumann N, Comi G, Gregson NA, et al. Inter-laboratory validation of an ELISA for the determination of serum anti-ganglioside antibodies. European Journal of Neurology 1999;6(1):71-7.

\section{Yuki 1993}

Yuki N, Yamazaki M, Kondo H, Suzuki K, Tsuji S. Treatment of multifocal motor neuropathy with a high dosage of intravenous immunoglobulin. Muscle and Nerve 1993;16(2):220-1.

\section{References to other published versions of this review}

\section{Kosa 2009}

Kosa S, Klein CJ. Infliximab associated motor neuropathy typically has monophasic improving course with drug discontinuation. Neurology 2009;72:A264.

\section{Umapathi 2002b}

Umapathi T, Hughes RA, Nobile-Orazio E, Léger JM. Immunosuppressive treatment for multifocal motor neuropathy. Cochrane Database of Systematic Reviews 2002, Issue 2. [DOI: 10.1002/14651858.CD003217]

\section{Umapathi 2005}

Umapathi T, Hughes RAC, Nobile-Orazio E, Léger JM. Immunosuppressant and immunomodulatory treatments for multifocal motor neuropathy. Cochrane Database of Systematic Reviews 2005, Issue 3. [DOI: 10.1002/ 14651858.CD003217.pub2]

\section{Umapathi 2009}

Umapathi T, Hughes RA, Nobile-Orazio E, Léger JM. Immunosuppressant and immunomodulatory treatments for multifocal motor neuropathy. Cochrane Database of Systematic Reviews 2009, Issue 1. [DOI: 10.1002/ 14651858.CD003217.pub3]

* Indicates the major publication for the study 


\section{CHARACTERISTICS OF STUDIES}

\section{Characteristics of included studies [ordered by study ID]}

\section{Piepers 2007}

\begin{tabular}{|c|c|c|}
\hline Methods & \multicolumn{2}{|c|}{ Double-blind, parallel-group, randomised trial } \\
\hline Participants & \multicolumn{2}{|c|}{$\begin{array}{l}28 \text { people with multifocal motor neuropathy at a single centre (Department of Neuro- } \\
\text { muscular Diseases, UMC Utrecht) } \\
\text { Male:female ratio, 13:1 and 11:3 (mycophenolate mofetil and placebo groups, respec- } \\
\text { tively); mean ages } 50 \text { (SD 8) and } 49 \text { (SD 8) years }\end{array}$} \\
\hline Interventions & \multicolumn{2}{|c|}{ Mycophenolate mofetil $1 \mathrm{~g}$ twice a day $(\mathrm{n}=14)$ or placebo $(\mathrm{n}=14)$ for 12 months } \\
\hline Outcomes & \multicolumn{2}{|c|}{$\begin{array}{l}\text { Primary outcome: } 50 \% \text { or more reduction of baseline mean weekly IVIg dose } \\
\text { Secondary outcomes: } \\
\text { - Improvement of muscle strength at } 3 \text { months (combined MRC scale of } 15 \\
\text { muscles on both sides) } \\
\text { - Improvement of functional status at } 3 \text { months using Guy's Neurological } \\
\text { Disability Scale (Sharrack 1999), the self evaluation scale (Léger 2001) and the nine- } \\
\text { hole peg test (Oxford 2003; Sharrack 1999) } \\
\text { - Reduction of IgM GM1 antibody titre after } 12 \text { months }\end{array}$} \\
\hline Funding & \multicolumn{2}{|c|}{$\begin{array}{l}\text { "MMF [mycophenolate mofetil] was obtained from Roche Pharmaceuticals, and MMF } \\
\text { and placebo were packed in identical capsules. MMF was obtained free from Roche. } \\
\text { Roche pharmaceuticals was not involved in the study design and did not support the } \\
\text { performance of the trial. All patients received the same brand of immunoglobulins; } \\
\text { Gammagard (Baxter)" }\end{array}$} \\
\hline Conflicts of interest & \multicolumn{2}{|c|}{ Declaration of interest not provided } \\
\hline \multicolumn{3}{|l|}{ Notes } \\
\hline \multicolumn{3}{|l|}{ Risk of bias } \\
\hline Bias & Authors' judgement & Support for judgement \\
\hline $\begin{array}{l}\text { Random sequence generation (selection } \\
\text { bias) }\end{array}$ & Low risk & $\begin{array}{l}\text { Participants were randomly assigned to re- } \\
\text { ceive either mycophenolate mofetil ( } 500 \\
\text { mg twice daily during the first week, } 1000 \\
\text { mg twice daily thereafter) or placebo. "Ran- } \\
\text { domisation was performed by one of the } \\
\text { investigators (RB), using block randomi- } \\
\text { sation with stratification for the extent } \\
\text { of muscle weakness at baseline (treatment } \\
\text { group A: MRC sum score }<95 \text {; treatment } \\
\text { group B: MRC sum score }>95) \text {. After allo- } \\
\text { cating the participants to one of the treat- } \\
\text { ment groups, each participant was given }\end{array}$ \\
\hline
\end{tabular}


Piepers 2007 (Continued)

a number ( 0 to 15 to participants allocated to treatment group A, numbers 16 to 30 to participants allocated to treatment group B). Randomisation numbers were passed on to the research pharmacist, who had randomly assigned mycophenolate mofetil/placebo to corresponding numbers. Only the research pharmacist had access to the trial codes. Trial medication was packed in blank containers and handed out to the participants. Neither investigators nor participants were aware of group assignment until the end of the trial". Randomisation considered adequate

Allocation concealment (selection bias) Low risk

Participants were randomly assigned to receive either mycophenolate mofetil $(500$ $\mathrm{mg}$ twice daily during the first week, 1000 $\mathrm{mg}$ twice daily thereafter) or placebo for a period of 12 months. "Mycophenolate mofetil was obtained from Roche Pharmaceuticals, and mycophenolate mofetil and placebo were packed in identical capsules. Mycophenolate mofetil was obtained free from Roche. Roche pharmaceuticals was not involved in the study design and did not support the performance of the trial. All participants received the same brand of immunoglobulins; Gammagard (Baxter) - Randomisation was performed by one of the investigators (RB), using block randomisation with stratification for the extent of muscle weakness at baseline (treatment group A: MRC sum score < 95; treatment group B: MRC sum score $>95$ ). After allocating the participants to one of the treatment groups, each participant was given a number ( 0 to 15 to participants allocated to treatment group $\mathrm{A}$, numbers 16 to 30 to participants allocated to treatment group B). Randomisation numbers were passed on to the research pharmacist, who had randomly assigned mycophenolate mofetil/placebo to corresponding numbers. Only the research pharmacist had access to the trial codes. Trial medication was packed in blank containers and handed out to the participants. Neither investiga-

Immunosuppressant and immunomodulatory treatments for multifocal motor neuropathy (Review) 
Piepers 2007 (Continued)

tors nor participants were aware of group assignment until the end of the trial." Allocation concealment considered adequate bias)

All outcomes
Blinding (performance bias and detection Low risk

Participants were randomly assigned to receive either mycophenolate mofetil (500 mg twice daily during the first week, 1000 $\mathrm{mg}$ twice daily thereafter) or placebo for a period of 12 months. Mycophenolate mofetil was obtained from Roche Pharmaceuticals, and mycophenolate mofetil and placebo were packed in identical capsules. Mycophenolate mofetil was obtained free from Roche. Roche pharmaceuticals was not involved in the study design and did not support the performance of the trial. All patients received the same brand of immunoglobulins; Gammagard (Baxter). Randomisation was performed by one of the investigators (RB), using block randomisation with stratification for the extent of muscle weakness at baseline (treatment group A: MRC sum score < 95; treatment group B: MRC sum score $>95)$ ). After allocating the patients to one of the treatment groups, each participant was given a number ( 0 to 15 to participants allocated to treatment group $A$, numbers 16 to 30 to participants allocated to treatment group B). Randomisation numbers were passed on to the research pharmacist, who had randomly assigned mycophenolate mofetil/placebo to corresponding numbers. Only the research pharmacist had access to the trial codes. Trial medication was packed in blank containers and handed out to the participants. Neither investigators nor participants were aware of group assignment until the end of the trial. Blinding considered adequate

Incomplete outcome data (attrition bias) Low risk All outcomes
Only one participant in each group was not followed up and included in the analysis (because of withdrawal of consent after 3 months). 1 participant each in treatment and placebo group withdrew, for "flu-like" symptoms and "unacceptable deterioration in muscle strength" respectively. Analysis was by "intention to treat" 
Piepers 2007 (Continued)

\begin{tabular}{l|l|l}
\hline Selective reporting (reporting bias) & Low risk & $\begin{array}{l}\text { There is no indication of selective reporting } \\
\text { in this study as all the outcomes decided } \\
\text { a priori were reported upon even though } \\
\text { none of them showed a positive outcome }\end{array}$ \\
\hline Other bias & Low risk & $\begin{array}{l}\text { "Neither investigators nor participants } \\
\text { were aware of group assignment until } \\
\text { the end of the trial". Baseline character- } \\
\text { istics comparable between treatment and } \\
\text { placebo groups }\end{array}$ \\
\hline
\end{tabular}

IVIg: intravenous immunoglobulin; IgM: immunoglobulin M; MRC: Medical Research Council. 
DATA ANDANALYSES

Comparison 1. Mycophenolate mofetil versus placebo

\begin{tabular}{lcclc} 
Outcome or subgroup title & $\begin{array}{c}\text { No. of } \\
\text { studies }\end{array}$ & $\begin{array}{c}\text { No. of } \\
\text { participants }\end{array}$ & Statistical method & Effect size \\
\hline $\begin{array}{l}\text { 1 Improvement in GNDS after 12 } \\
\text { months }\end{array}$ & 1 & 27 & Risk Ratio (M-H, Fixed, 95\% CI) & $0.54[0.06,5.26]$ \\
2 Serious adverse events & 1 & 28 & Risk Ratio (M-H, Fixed, 95\% CI) & $0.0[0.0,0.0]$ \\
\hline
\end{tabular}

Analysis I.I. Comparison I Mycophenolate mofetil versus placebo, Outcome I Improvement in GNDS after 12 months.

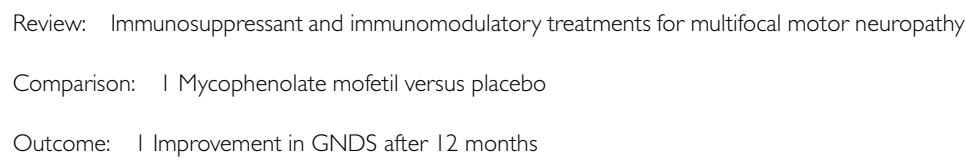

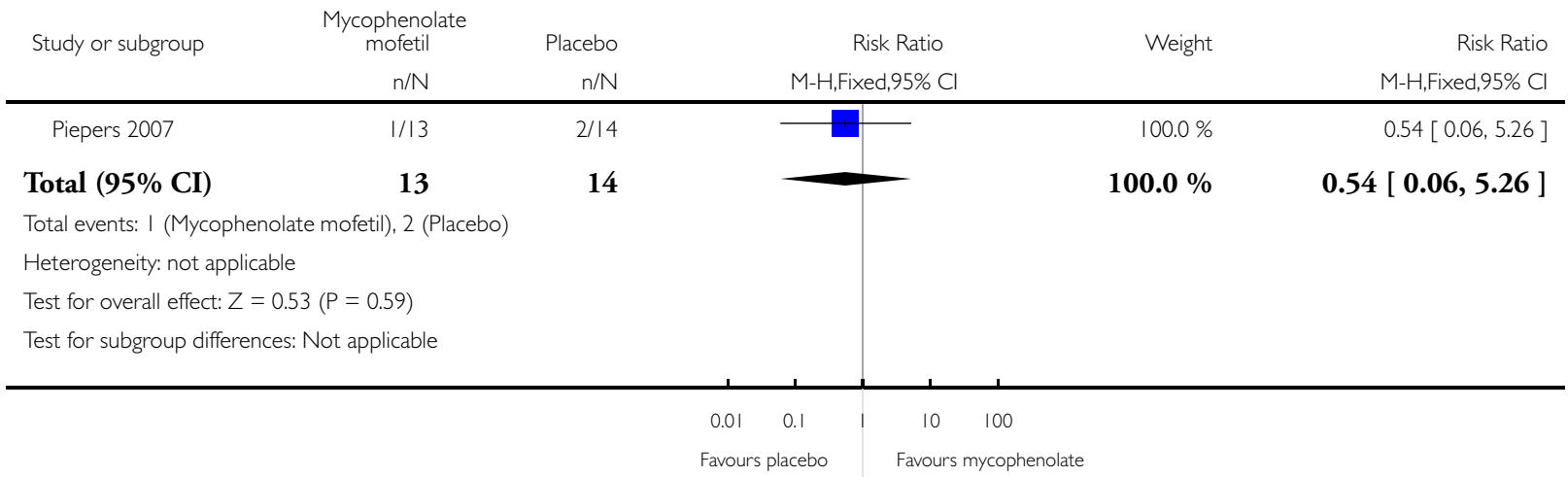




\section{Analysis I.2. Comparison I Mycophenolate mofetil versus placebo, Outcome 2 Serious adverse events.}

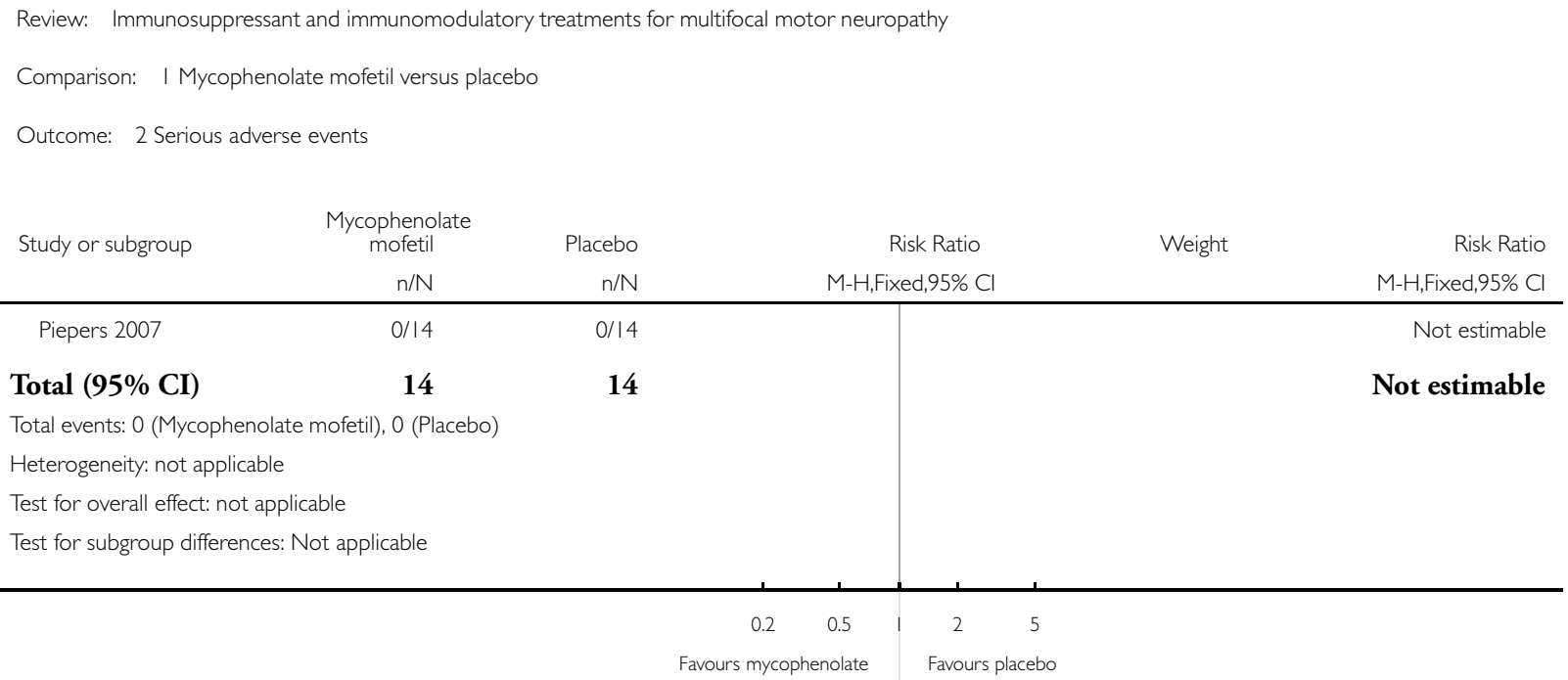

\section{ADDITIONAL TABLES}

\section{Table 1. Reports of lack of response to corticosteroids}

Krarup $1990 \quad$ None of 3 people with MMN on oral prednisolone improved. 1 person became weaker on a dose of $25 \mathrm{mg} /$ day

Charles 1992

1 person responded to IVIg after not responding to prednisolone $60 \mathrm{mg} / \mathrm{day}$ for 2 months

Kaji 1992.

1 person with MMN received oral prednisolone $50 \mathrm{mg} /$ day for 1 month followed by $200 \mathrm{mg} /$ week of intravenous methylprednisolone 2 days/week for two months, followed by twice weekly plasma exchange for weeks, and oral cyclophosphamide $100 \mathrm{mg} /$ day for one month. 1 person received oral prednisolone $50 \mathrm{mg} /$ day for three months. Neither improved but both responded to IVIg

Hausmanowa-Petrusewicz 19911 person with MMN did not respond to prednisone $80 \mathrm{mg} / \mathrm{d}$ but improved 12 months after starting azathioprine $100 \mathrm{mg} /$ day

Nobile-Orazio 1993

3 out of 5 people with MMN were treated with corticosteroids, with no effect in 2 and severe deterioration in 1

Jaspert 1996

2 people with MMN received corticosteroid without adequate clinical response but responded to IVIg

Abbruzzese 1997

1 person with MMN did not respond to prednisolone $50 \mathrm{mg} / \mathrm{d}$ for 4 weeks but responded to IVIg

Immunosuppressant and immunomodulatory treatments for multifocal motor neuropathy (Review) 
Table 2. Reports of worsening while on corticosteroids

\begin{tabular}{|c|c|}
\hline Donaghy 1994 & $\begin{array}{l}4 \text { person with MMN showed significant motor deterioration within } 4 \text { weeks of starting prednisolone } 60 \mathrm{mg} / \\
\text { day. In } 2 \text {, stopping the treatment reversed this acute decline }\end{array}$ \\
\hline Vrethem 1996 & $\begin{array}{l}1 \text { person with MMN did not respond to } 8 \text { plasma exchanges, possibly got worse on steroids; but improved } \\
\text { about one week after IVIg }\end{array}$ \\
\hline van den Berg 1997 & 2 person with MMN deteriorated on high-dose dexamethasone. They subsequently improved on IVIg \\
\hline Le Forestier 1997 & $\begin{array}{l}2 \text { person with } \mathrm{MMN} \text { worsened on corticosteroids. Corticosteroid treatment precipitated worsening in } 6 \text { of } 9 \\
\text { people. Two other people developed MMN only after the introduction of corticosteroids for another indication }\end{array}$ \\
\hline
\end{tabular}

Table 3. Reports of improvement of MMN while on corticosteroids.

\begin{tabular}{l|l}
\hline Parry 1988 & $\begin{array}{l}1 \text { person with MMN on } 60 \text { mg of prednisolone a day followed } \\
\text { later by the addition of azathioprine } 150 \mathrm{mg} / \mathrm{day}\end{array}$ \\
\hline de Carvalho 1997 & $\begin{array}{l}1 \text { person with MMN responded to low-dose corticosteroids. How- } \\
\text { ever, this person had raised cerebrospinal fluid protein (100 mg/ } \\
\text { dl) }\end{array}$ \\
\hline $\begin{array}{l}\text { Komiyama } 1998 \\
\begin{array}{l}1 \text { person with MMN responded to pulsed methylprednisolone } \\
\text { followed by maintenance prednisolone }\end{array}\end{array}$ & $\begin{array}{l}1 \text { person with MMN improved gradually while on plasma ex- } \\
\text { change and long-term corticosteroid therapy }\end{array}$ \\
\hline $\begin{array}{l}\text { Van den Bergh } 1989 \\
\text { Bentes } 1999 \text { (this individual is the same reported by de Carvalho }\end{array}$ & \begin{tabular}{l}
1 out of 9 people with MMN responded to corticosteroids \\
\hline
\end{tabular} \\
\hline
\end{tabular}




\section{A P P E N D I C E S}

\section{Appendix I. CRS search strategy}

\#1 “multifocal motor neuropath" [REFERENCE] [STANDARD]

\#2 “conduction block*" or "motor neuropath*” [REFERENCE] [STANDARD]

\#3 \#2 and multifocal [REFERENCE] [STANDARD]

\#4 \#1 or \#3 [REFERENCE] [STANDARD]

\#5 “immunosuppressive agent*” or "plasma exchange" or plasmapheresis [REFERENCE] [STANDARD]

\#6 azathioprine or cyclophosphamide or cyclosporin* or ciclosporin* or methotrexate or rituximab or eculizumab or infliximab [REFERENCE] [STANDARD]

\#7 MeSH DESCRIPTOR Adjuvants, Immunologic [REFERENCE] [STANDARD]

\#8 adjuvants NEAR immunologic [REFERENCE] [STANDARD]

\#9 immunomodulat* or interferon* or immunosuppress* mycophenolate or mycophenolic [REFERENCE] [STANDARD]

\#10 MeSH DESCRIPTOR Interferons Explode All [REFERENCE] [STANDARD]

\#11 irradiation NEAR lymph* [REFERENCE] [STANDARD]

\#12 "bone marrow transplant*" [REFERENCE] [STANDARD]

\#13 MeSH DESCRIPTOR Antibodies, Monoclonal Explode All [REFERENCE] [STANDARD]

\#14 monoclonal NEAR1 antibod* [REFERENCE] [STANDARD]

\#15 MeSH DESCRIPTOR Adrenal Cortex Hormones Explode All [REFERENCE] [STANDARD]

\#16 (subcutaneous NEAR4 immunoglobulin*) or scig [REFERENCE] [STANDARD]

$\# 17 \# 5$ or $\# 6$ or \#7 or \#8 or \#9 or \#10 or \#11 or \#12 or \#13 or \#14 or \#15 or \#16 [REFERENCE] [STANDARD]

$\# 18$ \#4 and \#17 [REFERENCE] [STANDARD]

\#19 (\#4 and \#17) AND (INREGISTER) [REFERENCE] [STANDARD]

\section{Appendix 2. CENTRAL search strategy}

\#1 "multifocal motor neuropathy" or "multifocal motor neuropathies"

\#2 "conduction block" or "conduction blocks" or "motor neuropathy" or "motor neuropathies"

$\# 3$ \#2 and multifocal

$\# 4 \# 1$ or \#3

\#5 MeSH descriptor: [Immunosuppressive Agents] explode all trees

\#6 “immunosuppressive agent" or "plasma exchange" or plasmapheresis or azathioprine or cyclophosphamide or cyclosporin or cy-

closporine or ciclosporine

\#7 methotrexate or rituximab or immunomodulat* or interferon*

\#8 MeSH descriptor: [Adjuvants, Immunologic] this term only

\#9 MeSH descriptor: [Interferons] explode all trees

\#10 "lymphatic irradiation" or immunosuppressant* "mycophenolic acid"

\#11 "bone marrow" near transplant*

\#12 MeSH descriptor: [Antibodies, Monoclonal] explode all trees

\#13 monoclonal near/1 antibod*

\#14 MeSH descriptor: [Adrenal Cortex Hormones] explode all trees

\#15 subcutaneous near/4 immunoglobulin*

\#16 scig

$\# 17 \# 5$ or $\# 6$ or $\# 7$ or $\# 8$ or $\# 9$ or \#10 or \#11 or \#12 or \#13 or \#14 or \#15 or \#16

$\# 18$ \#4 and \#17

Immunosuppressant and immunomodulatory treatments for multifocal motor neuropathy (Review) 


\section{Appendix 3. MEDLINE (OvidSP) search strategy}

Database: Ovid MEDLINE(R) <1946 to September Week 2 2014>

Search Strategy:

1 randomized controlled trial.pt. (388375)

2 controlled clinical trial.pt. (89809)

3 randomized.ab. (284414)

4 placebo.ab. (150745)

5 drug therapy.fs. (1744932)

6 randomly.ab. (201022)

7 trial.ab. (295504)

8 groups.ab. (1282228)

9 or/1-8 (3283677)

10 exp animals/ not humans.sh. (4011372)

119 not 10 (2797292)

12 multifocal motor neuropath\$.mp. (565)

13 conduction block\$.mp. (3256)

14 motor neuropathy.mp. (2381)

15 (13 or 14) and multifocal.mp. (712)

1612 or $15(716)$

17 (myeloma or lymphoma).sh. (44914)

1816 not 17 (715)

19 immunosuppressive agent\$.tw. (7960)

20 Immunosuppressive agents/ (77318)

21 plasma exchange.tw. or Plasma exchange/ (7137)

22 Azathioprine.tw. or AZATHIOPRINE/ (19232)

23 cyclophosphamide.tw. or CYCLOPHOSPHAMIDE/ (58019)

24 cyclosporin\$.tw. or Cyclosporine/ or ciclosporin\$.tw. (48990)

25 methotrexate.tw. or METHOTREXATE/ (41995)

26 rituximab.mp. (11689)

27 ADJUVANTS, IMMUNOLOGIC/ (32021)

28 immunomodulat\$.tw. (33892)

29 interferon.mp. or exp Interferons/ (154666)

30 Lymphatic Irradiation/ (1006)

31 lymph\$ irradiation.tw. (795)

32 bone marrow transplantation.tw. or Bone Marrow Transplantation/ (47705)

33 immunosuppressant\$.mp. (10074)

34 mycophenolate.mp. (8425)

35 Mycophenolic Acid/ (6277)

36 exp monoclonal antibodies/ (183667)

37 (monoclonal adj1 antibod\$).tw. (156804)

38 exp adrenal cortex hormones/ (341273)

39 ((subcutaneous adj4 immunoglobulin\$) or scig).mp. (202)

40 (eculizumab or infliximab).mp. (9415)

41 or/19-40 (960869)

4211 and 18 and 41 (112)

43 remove duplicates from 42 (107)

44 case reports.pt. (1713335)

4543 not 44 (73) 


\section{Appendix 4. EMBASE (OvidSP) search strategy}

Database: Embase <1980 to 2014 Week 38>

Search Strategy:

1 crossover-procedure.sh. (40222)

2 double-blind procedure.sh. (115438)

3 single-blind procedure.sh. (18827)

4 randomized controlled trial.sh. (350056)

5 (random\$ or crossover\$ or cross over\$ or placebo $\$$ or (doubl\$ adj blind\$) or allocat\$).tw,ot. (1060969)

6 trial.ti. (162680)

7 or/1-6 (1194282)

8 exp animal/ or exp invertebrate/ or animal.hw. or non human/ or nonhuman/ (20191835)

9 human/ or human cell/ or human tissue/ or normal human/ (15057329)

108 not $9(5167170)$

117 not 10 (1047318)

12 limit 11 to embase (860567)

13 multifocal motor neuropath\$.tw. (862)

14 (conduction block\$ or motor neuropath\$).mp. (8182)

1514 and multifocal.mp. (1191)

1613 or 15 (1191)

17 (myeloma or lymphoma).sh. (81376)

1816 not 17 (1163)

19 exp Immunosuppressive Agent/ (548291)

20 immunosuppressive agent $\$ 1$.tw. (10370)

21 plasma exchange.mp. or Plasmapheresis/ (28088)

22 AZATHIOPRINE/ or Azathioprine.mp. (72896)

23 CYCLOPHOSPHAMIDE/ or cyclophosphamide.mp. (165183)

24 CYCLOSPORIN/ or cyclosporin.mp. (126781)

25 methotrexate.mp. or METHOTREXATE/ (130384)

26 rituximab.mp. or RITUXIMAB/ (41757)

27 exp Immunological Adjuvant/ (24448)

28 (immunologic adj1 adjuvant\$1).mp. (183)

29 immunomodulation/ (54837)

30 immunomodulat\$3.tw. (48346)

31 exp interferon/ (349249)

32 interferon\$1.tw. (140818)

33 exp radiotherapy/ (374992)

34 lymph $\$ 4$ irradiation.tw. (929)

35 bone marrow transplantation.mp. or exp Bone Marrow Transplantation/ (59336)

36 exp monoclonal antibody/ (346492)

37 (monoclonal adj1 antibod\$).mp. (247766)

38 exp corticosteroid/ (691505)

39 (subcutaneous adj 4 immunoglobulin\$).mp. (434)

40 scig.mp. (318)

41 (eculizumab or infliximab).mp. (32518)

42 or/19-41 (2009227)

4312 and 18 and 42 (58)

44 remove duplicates from 43 (58)

45 limit 44 to $y r=$ "1986-Current" (58) 


\section{Appendix 5. LILACS search strategy}

("multifocal motor neuropathy" or "neuropatia motora multifocal" or ((“conduction block" or "conduction blocks" or "bloqueio de conducao" or "bloqueios de conducao" or "blanqueos de conduccion" or "motor neuropathy") and multifocal)) and (((PT: "Randomized Controlled Trial” or "Randomized Controlled trial” or "Ensayo Clínico Controlado Aleatorio" or "Ensaio Clínico Controlado Aleatório" or PT:"Controlled Clinical Trial" or "Ensayo Clínico Controlado" or "Ensaio Clínico Controlado" or "Random allocation" or "Distribución Aleatoria" or "Distribuição Aleatória" or randon\$ or Randomized or randomly or "double blind" or "duplo-cego" or "duplo-cego" or "single blind" or "simples-cego" or "simples cego" or placebo\$ or trial or groups) AND NOT (B01.050\$ AND NOT (humans or humanos or humanos))))

\section{WHAT'S NEW}

Last assessed as up-to-date: 22 September 2014.

\begin{tabular}{l|l|l}
\hline Date & Event & Description \\
\hline 22 December 2014 & $\begin{array}{l}\text { New citation required but conclusions have not } \\
\text { changed }\end{array}$ & New searches fully incorporated \\
\hline 22 September 2014 & New search has been performed & $\begin{array}{l}\text { All search strategies were updated and made more spe- } \\
\text { cific for MMN }\end{array}$ \\
\hline
\end{tabular}

\section{H I S T O R Y}

Protocol first published: Issue 3, 2001

Review first published: Issue 2, 2002

\begin{tabular}{l|l|l}
\hline Date & Event & Description \\
\hline 17 January 2012 & $\begin{array}{l}\text { New citation required but conclusions have not } \\
\text { changed }\end{array}$ & New searches fully incorporated \\
\hline 2 August 2011 & New search has been performed & $\begin{array}{l}\text { New searches were run but no new randomised con- } \\
\text { trolled trials identified. Updated non-randomised stud- } \\
\text { ies. 'Summary of findings' and 'Risk of bias' tables } \\
\text { added }\end{array}$ \\
\hline 8 October 2008 & New search has been performed & $\begin{array}{l}\text { Updated in 2008 to incorporate one new randomised } \\
\text { trial }\end{array}$ \\
\hline 8 October 2008 & New citation required and conclusions have changed & $\begin{array}{l}\text { Updated review to incorporate one new randomised } \\
\text { controlled trial }\end{array}$ \\
\hline 26 April 2008 & Amended & Converted to new review format.
\end{tabular}

Immunosuppressant and immunomodulatory treatments for multifocal motor neuropathy (Review) 

Cochrane Neuromuscular Disease Group trials register in February 2004, MEDLINE (January 1966 to end May 2004) and EMBASE (January 1980 to end May 2004). No randomised or quasi-randomised trials that met the selection criteria for the review were found. Additional non-randomised studies have been added to the Background and Discussion sections

\section{CONTRIBUTIONSOFAUTHORS}

TU wrote the first draft. All the authors commented on this and subsequent drafts and agreed the final text.

\section{DECLARATIONSOF INTEREST}

TU received honoraria for lecturing from Baxter and Menarini that were subsequently donated to charity.

RACH holds or has held consultancies with CSL Behring, Grifols and LFB which make intravenous immunoglobulin (IVIg) which is used as the main treatment for multifocal motor neuropathy (MMN) and also with Novartis which is conducting a trial of fingolimod in a related condition, chronic inflammatory demyelinating polyradiculoneuropathy (CIDP). He was the chief investigator of a trial investigating the efficacy of methotrexate in CIDP.

EN-O is the principal investigator of two trials sponsored by LFB on the use of IVIg in CIDP. He was the principal investigator in a randomised controlled trial (RCT) sponsored by Kedrion comparing the efficacy of intravenous steroids with IVIg in CIDP. He participated as local principal investigator in a spontaneous RCT comparing methotrexate with placebo in CIDP. He has received payment for service on the Scientific Advisory Board for Sponsored Meetings of Baxter Italy and CSL Behring Italy, on the scientific advisory board 'Kedrion Global Immunoglobulin Advisory Panel' for Kedrion Italy, and on the Steering Committee of a fingolimod trial in CIDP for Novartis Switzerland. He has received honoraria for lecturing from Baxter Italy, CSL Behring Italy, Grifols Spain and Kedrion Italy and travel support to attend Scientific Meetings from Kedrion Italy. He states that no part of the above mentioned financial support had any influence on his work in preparing this review.

The institution of J-ML Léger has received grants from CSL Behring France, CSL Behring Germany, LFB and Octapharma France (manufacturers of IVIg) for clinical trials; payment from CSL Behring France for membership of an advisory board; from LFB, CSL Behring France and Octapharma France for data monitoring board membership; from CSL Behring France, CSL Behring Germany, Baxter and Novartis for consultancy; from CSL Behring France, Spain and Germany, LFB, Baxter, Novartis, Biogen Idec and Kedrion for lectures in symposia; and from CSL Behring France and LFB for development of educational presentations. J-ML has received honoraria from LFB and Novartis France to attend American Academy of Neurology and Peripheral Nerve Society meetings. J-ML was the chief investigator of a randomised trial of IVIg funded by Immuno-AG and then Baxter. He is also the chief investigator of a retrospective study of the safety and efficacy of IVIg funded by Octapharma in multifocal motor neuropathy (not published yet); was the chief investigator of a randomised, double-blind trial of rituximab (Roche) in anti-myelin-associated glycoprotein (anti-MAG) neuropathy, and is the chief investigator of a single-arm study of IVIg funded by CSL Behring in CIDP. 


\section{SOURCES OF SUPPORT}

\section{Internal sources}

- King's College, London, UK.

\section{External sources}

- Donation from Mr and Mrs Chris Lazari, UK.

\section{DIFFERENCESBETWEEN PROTOCOLANDREVIEW}

'Summary of findings' and 'Risk of bias' tables added.

At this update we activated subheadings and expanded the methods section to address current Cochrane standards. We specified that there would be no language restrictions in the searches. We stated how we would have resolved any disagreements on study selection, data extraction and 'Risk of bias' assessment. We described how we would have assessed heterogeneity. We stated whether we would use a fixed-effect or random-effects model if conducting a meta-analysis.

\section{N D EX TERMS}

\section{Medical Subject Headings (MeSH)}

Drug Therapy, Combination [methods]; Immunoglobulins, Intravenous [ ${ }^{*}$ therapeutic use]; Immunologic Factors [ ${ }^{*}$ therapeutic use]; Immunosuppressive Agents [*therapeutic use]; Motor Neuron Disease [ ${ }^{*}$ drug therapy]; Mycophenolic Acid [*analogs \& derivatives; therapeutic use]; Polyneuropathies [*drug therapy]; Randomized Controlled Trials as Topic

\section{MeSH check words}

Humans 